\title{
AN INVESTIGATION INTO A SMALL WIND TURBINE BLADE DESIGN
}

\author{
by \\ Sayem Zafar, B.Eng., \\ Ryerson University, Toronto, Canada, 2008
}

A project presented to Ryerson University

in partial fulfillment of the requirements for the degree of

Master of Engineering

in the Program of

Aerospace Engineering

Toronto, Ontario, Canada, 2009

(C) Sayem Zafar 2009 
I hereby declare that I am the sole author of this thesis.

I authorize Ryerson University to lend this thesis or dissertation to other institutions or individuals for the purpose of scholarly research.

Sayem Zafar

I further authorize Ryerson University to reproduce this thesis by photocopying or by other means, in total or in part, at the request of other institutions or individuals for the purpose of scholarly research.

Sayem Zafar 


\title{
AN INVESTIGATION INTO A SMALL WIND TURBINE BLADE DESIGN
}

\author{
Master of Engineering, Aerospace Engineering, \\ Ryerson University, 2009
}

\section{Sayem Zafar}

\section{Abstract}

The objective of the project was to design a small wind turbine blade which is aerodynamically efficient and easy to manufacture. Preliminary aerodynamic analysis concluded NACA $63-425$ to be the most efficient airfoil. Blade geometry was determined after calculating baseline geometric values for low drag which was then used to calculate power. Blade's structural integrity was studied using ANSYS ${ }^{\circledR}$ software. Tested results yielded that a single layer of E-fibreglass-epoxy is good enough to sustain the prescribed loads. The results were used to calculate the total weight of the blade which was then used to determine the start-up speed.

Overall the project was successful in designing a wind turbine blade that produced 450 [W] of electrical power at $4[\mathrm{~m} / \mathrm{s}]$ wind speed with the start-up speed of around $2[\mathrm{~m} / \mathrm{s}]$. The project fulfilled its objective which was to design a more effective wind turbine blade with manufacturability in mind. 


\section{Acknowledgments}

I would like to acknowledge my project supervisor, Professor Seyed M. Hashemi, for all his assistance and guidance throughout the project research. I would like to thank Professor J. Lassaline and Professor P. Walsh for all their help throughout the project. I also would like to thank my friend, Mohsin Afridi, for his assistance with my project. A special thank to my family since this work could not have been possible without their support. Finally, I would like to thank Ryerson University for providing me with the opportunity to continue with my graduate studies. 


\section{Table of Contents}

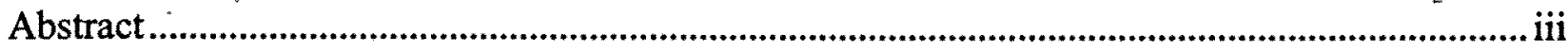

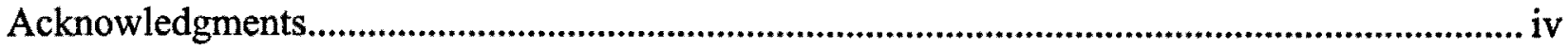

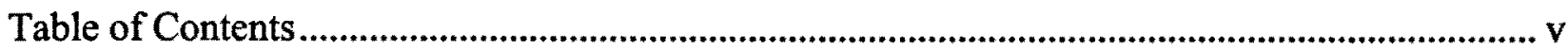

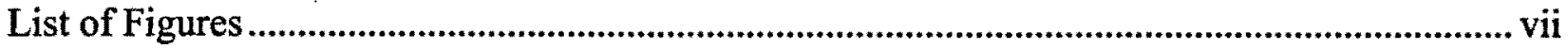

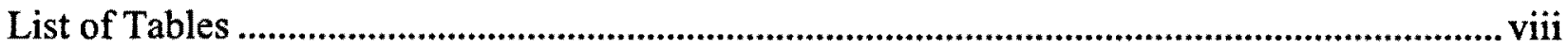

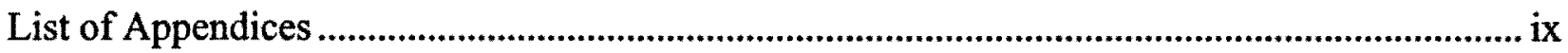

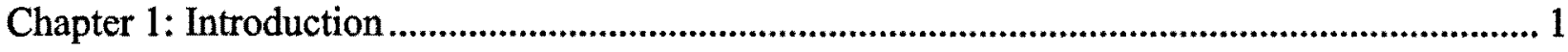

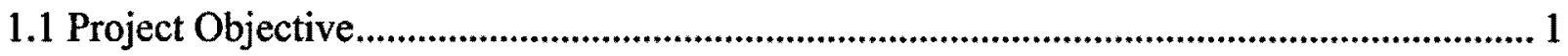

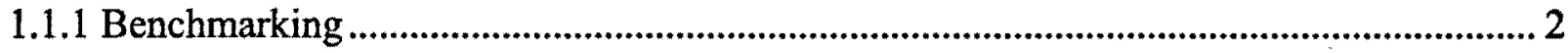

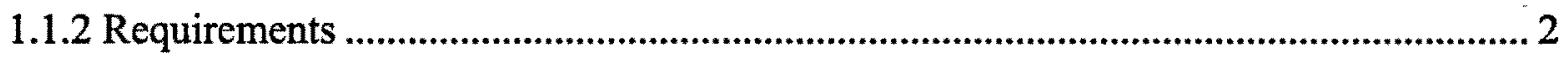

1.2 Literature Survey

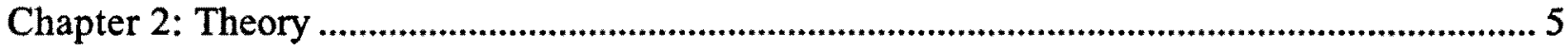

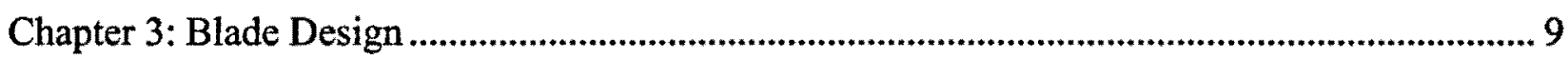

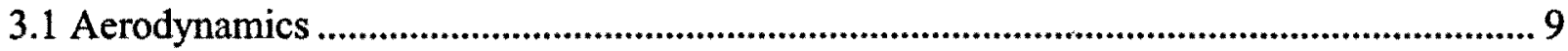

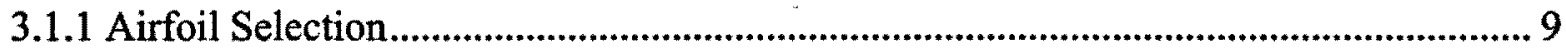

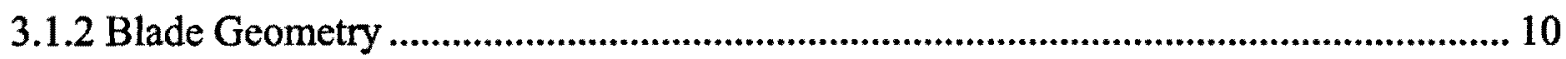

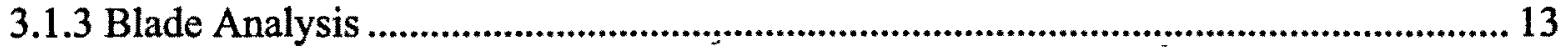

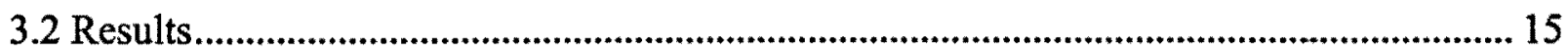

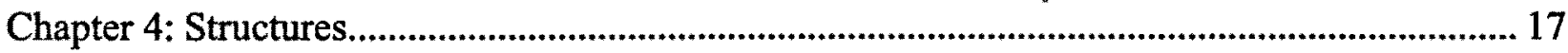

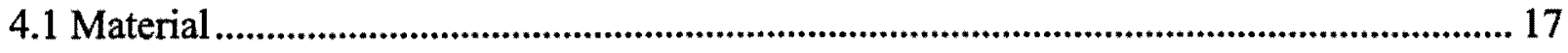

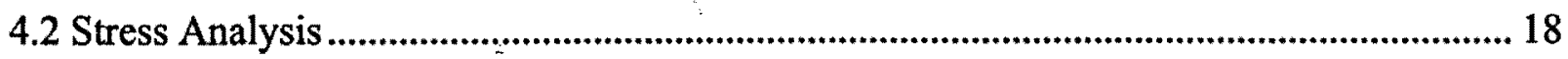

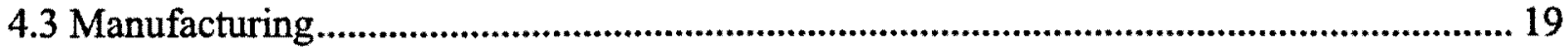




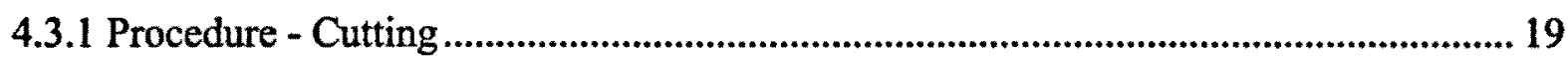

4.3.2 Procedure - Moulding...................................................................................................... 19

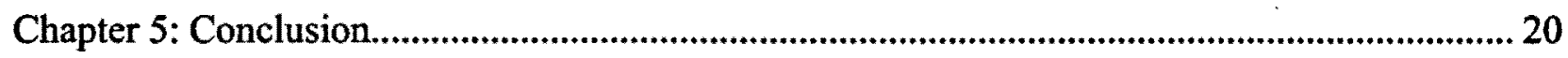

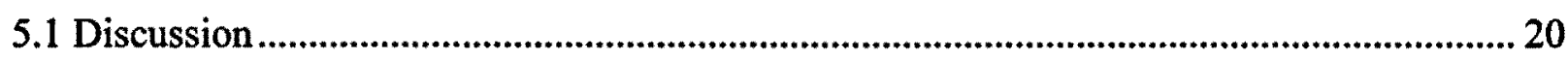

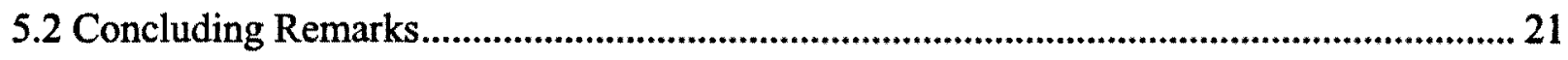

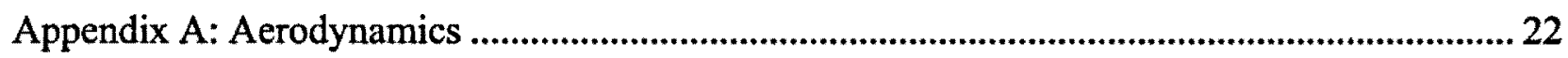

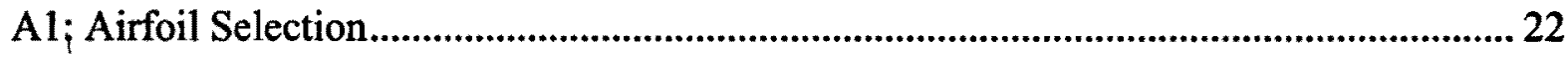

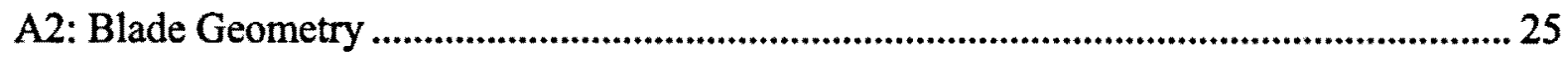

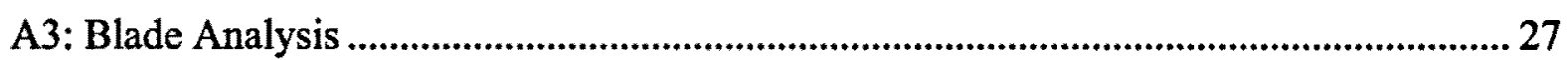

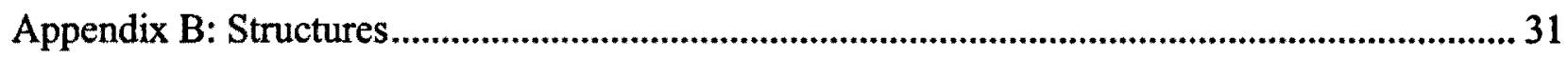

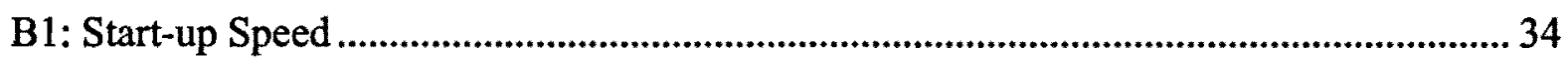

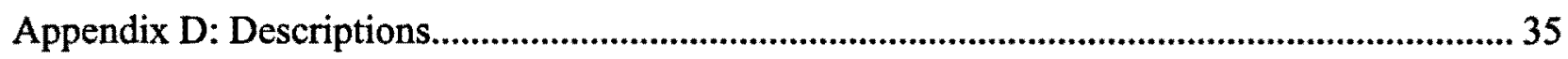

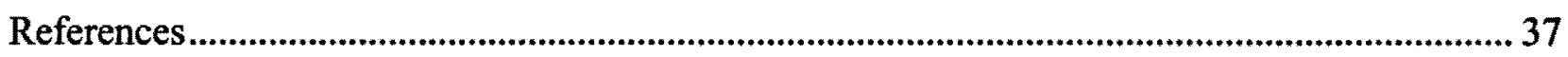




\section{List of Figures}

Figure 1: Figure shows 1-D momentum theory for wind turbine .................................................. 5

Figure 2: Control volume for the flow around the actuator disc [4] ............................................. 6

Figure 3: Change in NACA 63-425 airfoil's L/D ratio with respect to angle of attack................ 11

Figure 4: L/D ratio plotted against angle of attack for multiple airfoils...................................... 22

Figure 5: $L / D$ bucket of NACA 64-412 airfoil for multiple Reynolds's number. .......................... 23

Figure 6: $L / D$ bucket of NACA 63-425 airfoil for multiple Reynolds's number. .......................... 23

Figure 7: Flow separation point comparison for different airfoils with respect to increment in

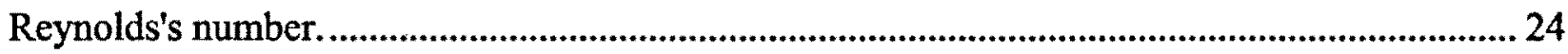

Figure 8: Visual representation of chord values as it increases with the span................................ 26

Figure 9: Spanwise lift distribution and the equation of the curve ................................................. 28

Figure 10: Lift coefficient distribution along the span of the designed blade ................................. 28

Figure 11: Spanwise drag distribution and the equation of the curve.............................................. 29

Figure 12: Spanwise torque and the equation of the curve.............................................................30

Figure 13: Blade loading test to determine equivalent stress for optimal thickness...................... 32

Figure 14: Blade bending test to determine maximum tip deflection............................................32

Figure 15: Torsion test to determine the maximum twist deflection.................................................33

Figure 16: Blade's torsion test to determine if the maximum twist can be sustained .....................34 


\section{List of Tables}

Table 1: Technical specifications of Whisper 200[9] wind turbine.............................................. 2

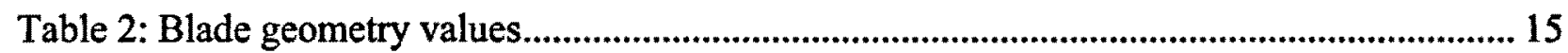

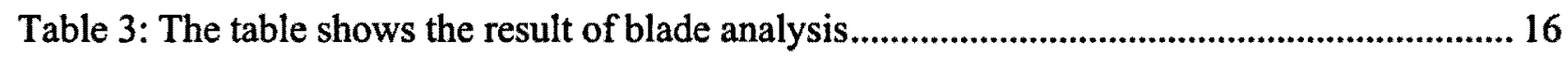

Table 4: Typical properties of E-fibreglass-epoxy at room temperature [6] .................................. 17

Table 5; Test results of stress analysis on the designed turbine blade........................................... 18

Table 6: Table shows the comparison between the designed model and the traditional turbine.. 20

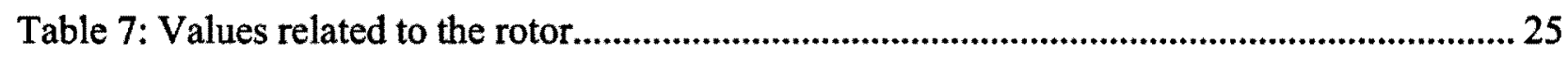

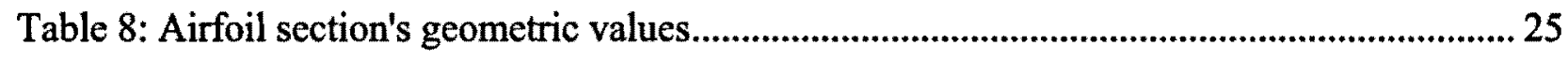

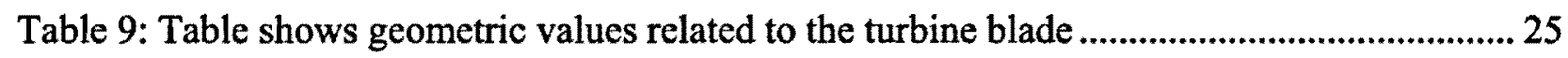

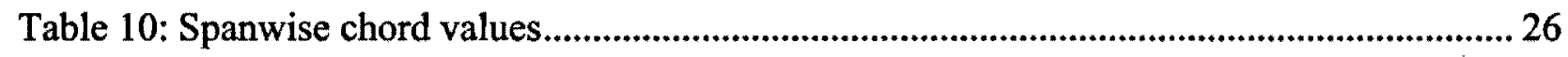

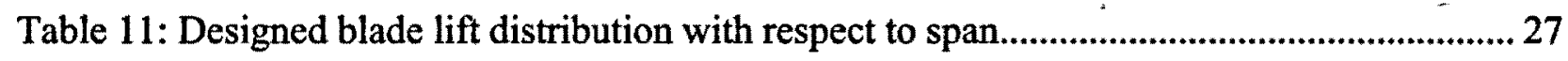

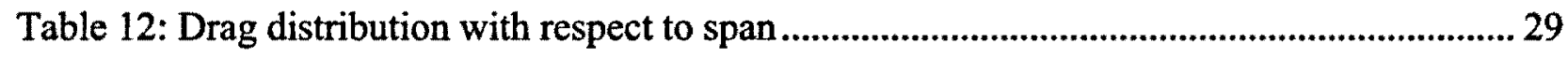

Table 13: Total and fractional weight of the designed blade............................................................ 34 


\section{List of Appendices}

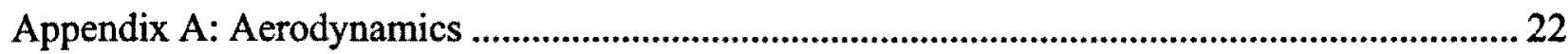

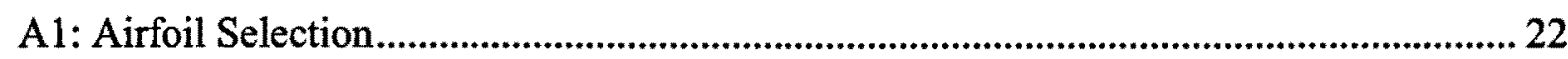

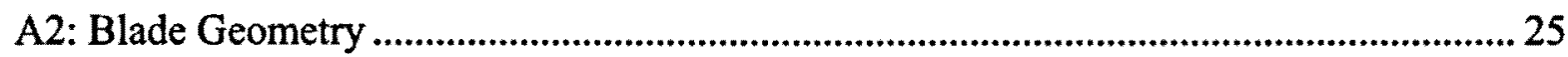

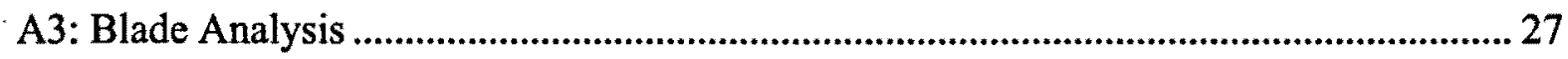

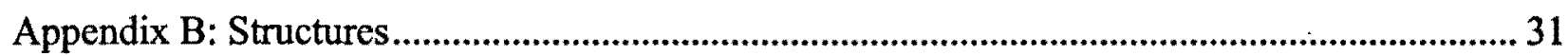

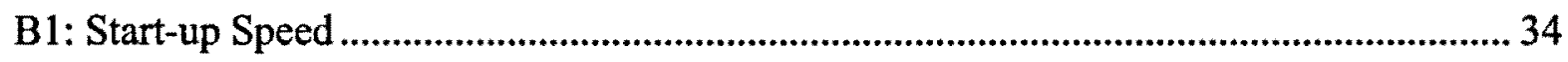

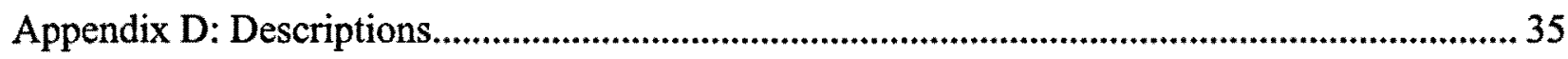

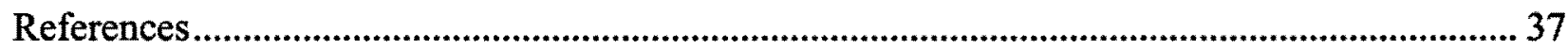




\section{Chapter 1: Introduction}

Global reliance on energy has increased many folds over the last few decades and it continues to do so, at an alarming rate. In order to meet the growing energy demand, natural resources are being depleted faster than they can be replenished. Destruction of natural resources can be associated not only to global increase in energy demand but also to our heavy reliance on nonrenewable sources of energy. To ensure the stability of global climate and natural resources, it is required to move towards renewable energy sources that have minimal environmental side effects.

Due to the advancements made in aerospace sciences during the last century, the most costeffective way to generate renewable energy is through wind. Wind energy generation is environmentally friendly as it has a minimal environmental impact with no hazardous emission. Although there are many different ways to generate electricity but none is more efficient than capturing wind energy using horizontal-axis wind turbine.

A horizontal axis wind turbine is a wind turbine in which the axis of the rotor's rotation is parallel to the wind stream and the ground. The purpose of the rotor is to convert the linear motion of the wind into rotational energy that can be used to drive a generator. Rotors are comprised of a finite number of blades. For modern wind turbines, the blades are aerodynamically shaped to produce highest lift possible, which converts to higher torque values resulting in increased power generation. In other words, efficient blade design can significantly increase the power output of a wind turbine.

\subsection{Project Objective}

The objective of this project was to design a wind turbine blade which can be used for a small wind turbine to yield maximum possible power and have a low start-up speed. 


\subsubsection{Benchmarking}

In order to have an idea as to what performance should the designed blade yield, an existing small wind turbine was used as a comparison. A benchmark was set to compare the performance with the existing design so that the new design would be acceptable in the market. A new turbine blade yielding lower or even same performance would not be in demand.

Whisper 200[9] was used as a benchmark as it is available in the Canadian market and it can be used as a personal use wind turbine because of its small blade span. Table 1 shows some of the technical specifications of Whisper 200[9].

Table 1: Technical specifications of Whisper 200[9] wind turbine

\begin{tabular}{|l|c|}
\hline Start-Up Speed & $3.1[\mathrm{~m} / \mathrm{s}]$ \\
\hline Blade Span & $1.35[\mathrm{~m}]$ \\
\hline Electrical Power at $4[\mathrm{~m} / \mathrm{s}]$ wind & $180[\mathrm{~W}]$ \\
\hline
\end{tabular}

\subsubsection{Requirements}

The aim of this project was to design a blade that enables better performance as compared to the one yielded by Whisper 200[9]; shown in Table 1. The requirements for this project were;

- To have a blade design that yields more than 180 [W] powers at $4[\mathrm{~m} / \mathrm{s}]$ winds with a 3 blade configuration.

- Blade span must be limited to $1.5[\mathrm{~m}]$ so that the turbine can still be used for personal use.

- The blade must start rotating at wind speeds below $3.1[\mathrm{~m} / \mathrm{s}]$. 


\subsection{Literature Survey}

The project was initiated by reviewing available literature on wind turbine blade design. The report is aimed as a tool to help with design and analysis of small wind-turbine blade. The blade under design is classified as "small wind turbine" blade by Clarke [1] on behalf of government of Ontario. Before any preliminary design analysis could be conducted, a general idea of the whole concept of designing a wind turbine blade was researched. The survey focuses on basic blade design parameters with an overview on aerodynamics, material and structural analysis.

Aerodynamics play an important role in determining the efficiency of a wind-turbine blade as this is where the kinetic energy in the wind, transforms into mechanical energy. An efficient wind turbine blade is one that produces high lift with relatively low drag for a desired range of Reynolds's number.

Raymer [6] proposes using 63-series airfoil for low Reynolds number laminar flow cases. Van Rooij and Timmer [9] suggest NACA 63-series airfoils can be used as effective HWAT (Horizontal Axis Wind Turbine) blade design airfoils. Van Rooij and Timmer [9] also presented that their newly designed airfoil is designed using NACA 63-425 as the reference, concluding that NACA 63-425 is the most efficient general aviation airfoil for wind turbine use.

This part gives an overview of literatures used for initial sizing and key geometric parameters of a blade. Hau [5] gives solidity values for different blade configurations and different sizes. Solidity, being the ratio of areas of the blades with respect to the actuator disc area, helped determine the planform area of the blade.

Another geometric parameter of the blade was its spanwise twist angle. This parameter was the hardest to analyse since the velocity triangles change the relative angle of attack of the blade hence severely affecting the blade's performance. Standard optimized twist distribution equations yield high performing small turbine blades but they are the slowest to start. CliftonSmith and Wood [12] optimized twist angle for small turbine blades and established baseline chord lengths for an efficient blade. 
Analysis of the governing equations of a wind turbine performance was an integral part of the project. Burton et al. [10] describe the governing equations for lift and drag to be used to find the total torque generated by the blade. Hau [5] lists the loads experienced by a wind turbine blade, namely aerodynamic, gravitational and inertial forces. Young [13] demonstrates the use of governing aerodynamic equations to determine the torque of the designed blade. Young [13] was also a good source to compare the results for lift, drag and torque generated by the blade.

A general idea of the whole concept of designing a wind turbine blade was researched to get an idea as to what to expect. Hau [5] had a lot of interesting information about types of material suitable for manufacturing a wind turbine blade, primarily, due to the experience gained from aircraft engineering. Raymer [6] gives specific data regarding the material properties of different materials used in aircraft industry. Raymer [6] and Young [13] explained the process of structural analysis that can be implemented when dealing with a wind turbine blade. The structural analysis appeared very similar to that for aircraft wing.

The project is to design an efficient blade for small wind turbine to produce a better power output than the ones available in the market. It was also desired to have a blade design which is easy and inexpensive to produce. Most of the small wind turbines available, in literature or in the market, either use impulsive blading or old NACA 4-series airfoils. Young [13] proved very useful since the report had the final calculated results included in it.

Overall the literature survey was successful in determining the literature requirements of the project while establishing a benchmark to compare with. The survey validated the results for the airfoil selection while some of the geometric parameters were extracted from the literature. Literature reviewed also helped understand the aerodynamics behind the turbine blade and defined how to do the structural analysis. 


\section{Chapter 2: Theory.}

In order to design a turbine blade, 1-D momentum theory for an ideal rotor was initially used. Wind turbine rotor disc is where wind's kinetic energy is converted to mechanical energy which intern rotates the turbine. The rotor is assumed to be frictionless and considered to have no rotational velocity component in the wake. Such conditions are described as ideal [4]. As shown in Figure 1, the rotor disc acts as a drag device slowing the wind speed from $V_{0}$, far upstream of the rotor, to $U$ at the rotor plane.

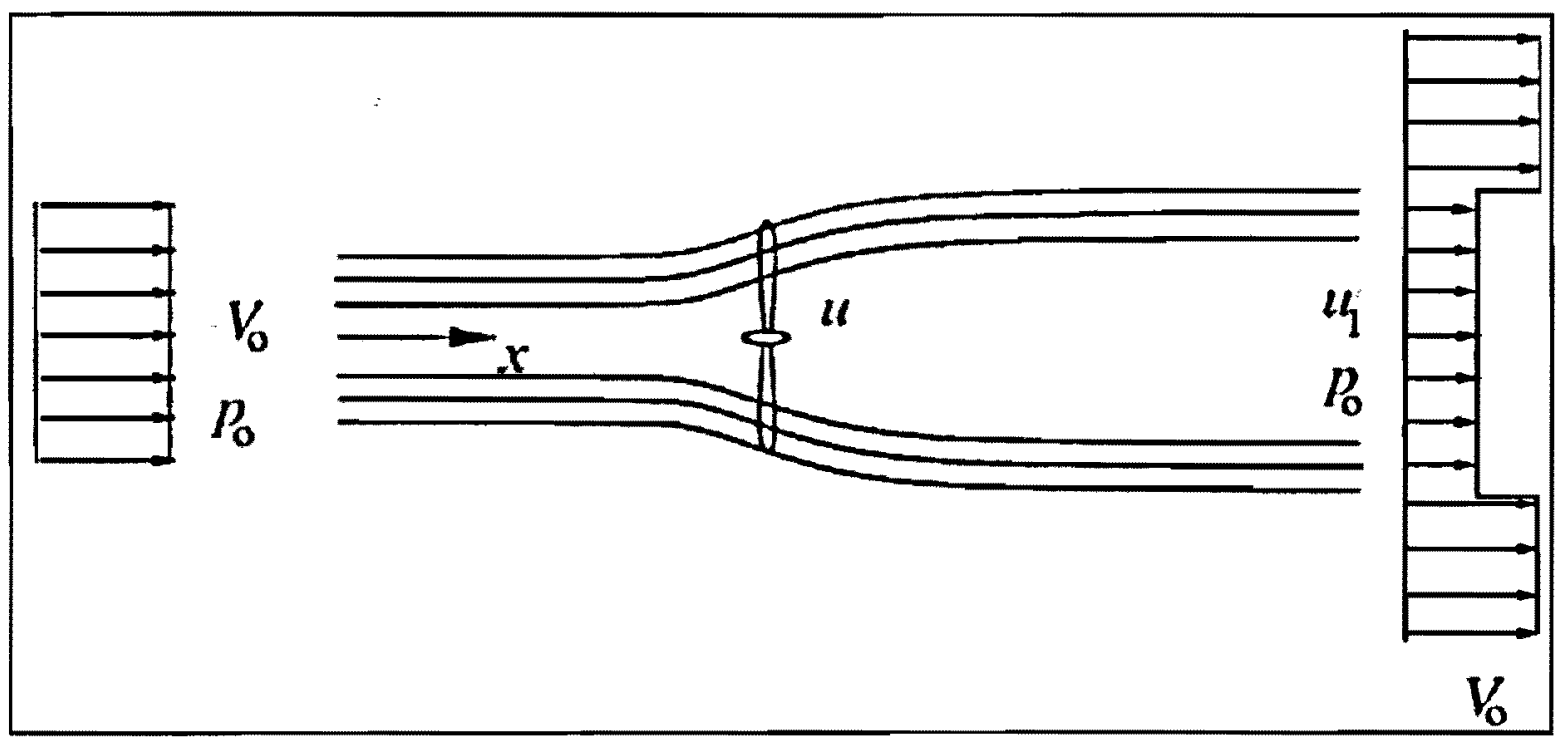

Figure 1: Figure shows 1-D momentum theory for wind turbine

Close upstream of the rotor, a small pressure rise occurs from the atmospheric level $p_{0}$ to $p$ because of the streamline divergence just before the disc. Just across the disc, a discontinuous pressure change $\Delta p$ occurs before downstream of the rotor, the pressure recovers continuously to the atmospheric level. Applying continuity with change in density being negligible, the velocity $V_{0}$ decreases to $U_{l}$. Figure 2 illustrates the above described phenomenon.

Using continuity equation to describe mass flow rate, $\dot{m}$ as;

$$
\dot{n}=\rho v A
$$


where

$\rho$ is density,

' $v$ ' is the fluid velocity and

' $A$ ' is the cross-section area

Considering the above described assumptions of ideal rotor with no external force acting on the fluid, Bernoulli equation can be applied from far upstream to just in front of the rotor and from just behind the rotor to far downstream in the wake to yield the absorbed shaft power $P$.

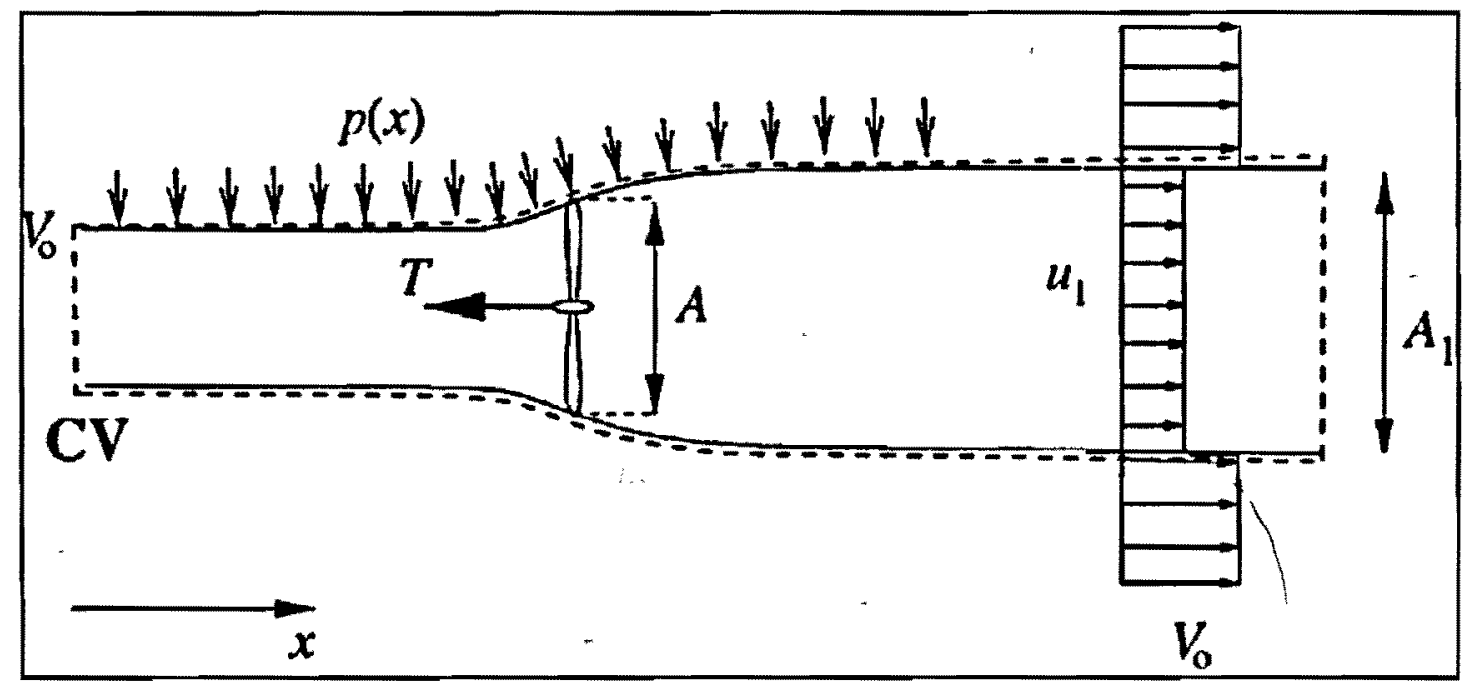

Figure 2: Control volume for the flow around the actuator disc [4].

Using the equation for thrust, $T$, for subsonic speeds [3];

$$
T=\dot{h} t\left(V_{\text {exit }}-V_{\text {inlet }}\right)
$$

Equation 2 is a standard equation for thrust, $T$, which is described as a product of mass flow rate, $\dot{\mathrm{m}}$, and the difference in inlet velocity, $V_{\text {inlet }}$, and the exit velocity, $V_{\text {exit }}$ Equation 2 yields thrust in positive $x$-direction. If the same equation is applied to the condition showed in Figure 2, it yields;

$$
T=\dot{m}\left(V_{0}-U_{1}\right)
$$


Equation 3 gives thrust in negative $\mathrm{x}$-direction, opposite to that of the free stream air, as compared to positive $x$-direction in Equation 2. This is an important distinction between an aircraft propeller and a wind turbine rotor.

Within the control volume shown in Figure 2, the flow is assumed to be frictionless and therefore assumed to have no change in the internal energy from the inlet to the outlet. Along with the assumption of negligible internal energy, change in potential energy is also ignored. Using the described assumptions, the shaft power ' $P$ ' can be found using the energy equation;

$$
P=\frac{1}{2} h\left(V_{0}^{2}-U_{1}^{2}\right)
$$

As evident from the above equation, extracted power not only depends on how much area is swept but also how much of the air is slowed downstream of the rotor. For an axial wind turbine, axial induction factor ' $a$ ' is defined as;

$$
a=\frac{V_{0}-U_{s}}{2 V_{0}}=\frac{V_{0}-U}{V_{0}}
$$

Axial induction factor indicates the energy extracted by the rotor from the air. This is one of the factors that set apart different turbines of the same size. Substituting Equation 5 into Equation 4 yields;

$$
P=2 \rho V_{0}^{3} A a(1-a)^{2}
$$

Equation 6 determines the power, $P$, that can be extracted from a wind turbine rotor, with ' $A$ ' being the cross-sectional area swept by the rotor. The power available in the wind can be described using the following equation;

$$
P_{\text {avail }}=\frac{1}{2} \rho A V_{0}^{3}
$$

The power $P$ is non-dimensionalized with respect to $P_{\text {avail }}$ as a power coefficient;

$$
C_{P} \frac{P}{\frac{2}{8} \rho A P_{0}^{\mathrm{B}}}
$$

Using Equation 5, the power coefficient for the ideal 1-D wind turbine may be written as; 


$$
C_{P}=4 a(1-a)^{2}
$$

Differentiating the above equation with respect to ' $a$ ' yields a maximum value of 0.59 for $C_{P}$ which is known as the Betz limit. Betz limit is the theoretical maximum power efficiency that can be achieved by a wind turbine which occurs when axial induction factor is 0.33 .

Power, $P$, can also be described as a product of torque, $Q$, and rotational speed, $\omega$;

$$
P=\omega \cdot Q
$$

Equation 10 suggests that power increases linearly with, either, the increase in torque or in rotational speed. It is a very important equation as it determined the direction of this project.

8 


\section{Chapter 3: Blade Design}

The aim of this project was to design an efficient wind turbine blade to be able to produce highest power possible with the ability to start producing torque at relatively low wind speeds. This section of the report focuses on the design considerations and analysis performed to achieve the optimal design for the blade.

\subsection{Aerodynamics}

Aerodynamics plays the most important role in the design of a wind turbine as it determines the total lift, hence the overall power production capability of the blade. This part gives an insight into the airfoil selection considerations, blade geometry analysis along with the overall aerodynamic analysis of the blade. The analysis was conducted using yearly average wind speeds, of $4[\mathrm{~m} / \mathrm{s}]$, for city of Toronto [11].

\subsubsection{Airfoil Selection}

The airfoil is critical to the blade design as it affects the aerodynamic efficiency. Airfoil selection was mainly determined by the need to achieve optimal aerodynamic efficiency for a wide range of blade's operating conditions. In order to have a blade that rotates in the presence of the lightest wind and that at high speed, it was desired to have a high lift to drag ratio. It was also desired to have a high $C_{L}$ for wide range of wind speeds and angles. Lastly, airfoils were compared for their high $C_{L \max }$. Pitching moment effect was considered to be negligible because of small geometry of the blade and low operating Reynolds number.

Considering the requirements for the wind turbine blade and reviewing the literature, it was concluded that laminar-flow airfoils are the ones best suited for the role. Laminar-flow airfoils maintain greater percentage of chord-wise laminar flow and control the transition point. They are designed so that the majority of the flow experienced by the airfoil is laminar as the separation point is reached further aft on airfoil, ultimately reducing negative effects caused by flow separation. Also, due to their large regions of laminar flow they produce less drag than other airfoils at low speed. The NACA 6-Series were designed with maximizing laminar flow in mind. 
With the above described objectives, handful of airfoils was selected to conduct further analysis as sown in Appendix A.

Tip section airfoil had to be slightly different than the one used for the root because of different requirements. One of the safety consideration needs to be incorporated in the design is the blade's ability to not exceed the designed maximum operating rotational speed. In order to achieve that requirement, blade has to stall at extremely high wind speeds. High speed stall can be achieved by having a relatively thin airfoil for the tip. For thin airfoils, the flow separation point starts traveling towards the leading edge as the wind speed increases, stalling the tip section of the blade hence reducing the total lift. The airfoil at the blade tip had to be thin enough to stall at high wind speeds yet thick enough not to cause a sudden stall. After careful consideration and conducting airfoil analysis using JavaFOIL [16] and DesignFOIL [15], it was decided to use NACA $63-425$ for the root and NACA 63-415 for the blade tip.

\subsubsection{Blade Geometry}

Once the airfoils for the blade were identified, blade geometry was determined. Blade span, $b$, was fixed to be $1.5[\mathrm{~m}]$ since the blade is for "very small turbine". To assess the design parameters, literature was reviewed to establish baseline values for the blade geometry. Using the parameters described below, efficient blade geometry values were determined and tabulated in Table 1.

\section{Angle of Attack - $\boldsymbol{\alpha}$}

After selecting the airfoil, angle of attack needed to be determined. The airfoil was analysed for multiple Reynolds's number to determine the angle of attack where highest lift to drag ratio exist. Figure 3 shows the effect of lift-to-rag ratio with respect to the increment in Reynolds number. It is evident from Figure 3 that the highest stable lift-to-drag ratio is achieved at 7 [deg] for NACA 63-425. Because of the above mentioned consideration, designed angle of attack for the wind turbine blade was chosen to be 7 [deg]. 


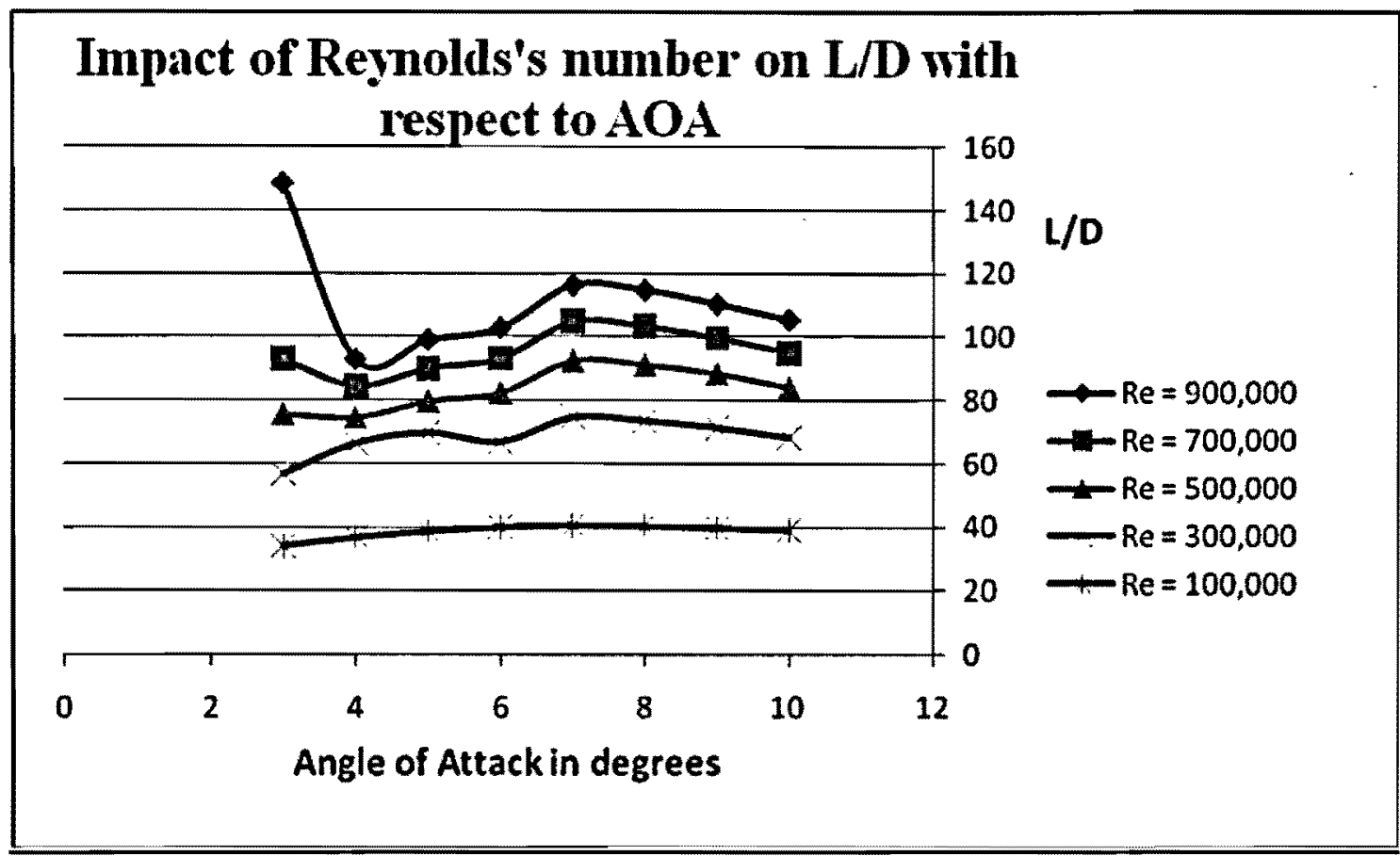

Figure 3: Change in NACA 63-425 airfoil's L/D ratio with respect to angle of attack.

\section{Aspect Ratio - AR}

Aspect ratio is a ratio between the blade span squared to the planform area of the blade. The equation that relates aspect ratio to other geometric parameters is as follows;

$$
\mathbf{A R}=\frac{b^{2}}{s}
$$

An aerodynamic trend was found leaning towards high aspect ratio because of being an efficient way to reduce drag. Values found in the literature suggested a range of 8 to 10; higher the better.

\section{Solidity - $\sigma$}

Solidity is the ratio of the total wetted blade area to the actuator disc area. This was used to find the planform area using the solidity of 0.1 [10]. For a 3-blade wind turbine, the equation comes out to be as follows;

$$
\sigma=\frac{85}{\pi t^{2}}
$$




\section{Taper Ratio $-\lambda$}

Taper ratio is the ratio between the tip-chord to the root-chord. The ratio is one for straight rectangular blade and described as follows;

$$
\lambda=\frac{c_{l l g}}{c_{300 t}}
$$

The blade cannot have the same chord length at the tip since it would be structurally unfeasible to have a high value of weight at the tip as it would increase the centrifugal force. Strongly tapered blades have smaller tip deflections due to large root chord giving a greater local stiffness and small root bending factor. Strongly tapered blades are desired for use in wind turbines since they stall under high speed. It occurs since the blade would already be operating at maximum local $C_{l}$ hence would stall under high speed. Stall is achieved since smaller chord causes the Reynolds's number to be low hence lower $C_{l}$ at the tip.

\section{Tip Speed Ratio - $\Omega$}

For most large wind turbines, it is one of the design parameters to optimise for. For small wind turbines, the highest tip speed value is hard to achieve as it would jeopardize other parameters. Tip speed ratio is defined as the ratio between the blade tip speed and the freestream wind;

$$
\Omega=\frac{v_{t u p}}{V_{0}}
$$

\section{Twist Angle - $\beta$}

Twist angles are usually determined through velocity triangles. It is the tangent inverse of the ratio of the air speed to the tangential speed of the blade section.

$$
\tan \beta=\frac{V_{0}}{V_{\theta}}
$$

Although an equation exist to determine the blade twist, the values determined using the equation are not the most optimal for a small blade design. Twist on a small wind turbine blade was given by Clifton-Smith and Wood [12]. The before mentioned literature has small turbine blade twist value optimized for low starting speed and maximum possible power. 


\subsubsection{Blade Analysis}

As discussed earlier, the aim of the analysis was to determine a design that yields the highest power output. Power depends on torque which in turn depends on lift and drag. The following section discusses approach for 3-D aerodynamics, and its implementation to determine lift, drag and torque for the blade. The values determined through the analysis are listed in Table 2.

\section{Lift}

3-D aerodynamics deals with the spanwise effect on the airfoil's aerodynamic coefficients. Lift is particularly important since lift coefficient does not remain the same for a finite structure. Since a blade is a structure of finite length with airfoil cross-sections, a pressure difference between the lower and upper sides is created, producing lift. At the tips, air flows around the tips from the lower side to the upper side because of the difference in pressure. This phenomenon causes a flow component in the spanwise direction, affecting the chord-wise streamline. Because of the disturbance, airfoil lift coefficient is not the same as that of the whole blade.

The governing equations used to solve the problem come from the standard vortex-lattice theory. The law of Biot-Savart was used to get the flow field around a finite straight vortex line, one of the basic vortex segments needed for the lattice [4]. These vortices induce a flow field in the air, and their strength was determined by the boundary conditions that no air flows through the wings. The forces acting on each vortex segment can be determined by employing the KuttaJukovski theorem. These forces may then be integrated to yield a composite force in three dimensions, which in turn used to compute aerodynamic coefficients.

3-D lift coefficient was of the utmost concern. Using the above described theory, blade lift coefficient was determined. Once the lift coefficient was determined, total lift generated by the blade was determined using the following equation;

$$
\mathrm{L}=\int_{\text {rosesta }}^{\operatorname{tat}} \in V_{0}^{2} \alpha\left(C_{L}\right) d r
$$




\section{Drag}

Subsonic airfoils experience drag due to different reasons. The dominant drag for low subsonic speed wing is induced drag, which is due to the lift component. The other form of drag is the parasite drag, which exist because to the skin friction plus a small viscous pressure separation. Since the parasitical drag component is relatively small with the pressure separation factor even smaller, tip leakage for the finite blade can be considered negligible. This consideration allows for the use of the same profile drag coefficient for the blade, as for the airfoil.

where;

$$
C_{D}=C_{d}+C_{L}^{2} K
$$

$$
K=\frac{1}{\pi \mathrm{ras}}
$$

Using the airfoil analysis software, parasite drag coefficient was determined for the desired conditions. Once the parasite drag coefficient was known, induced drag was calculated using the lift coefficient to determine the overall drag coefficient. Using the equation mentioned below, total drag on the blade was determined.

$$
D=\int_{\text {roo: } 2}^{\cos } e V_{0}^{2} \alpha\left(C_{D}\right) d r
$$

\section{Pitching Moment}

It is the moment that causes the blade to twist. Pitching moment increases with the increase in the flow and can pose a structural challenge. Although airfoil was selected to have high lift and low drag, moment coefficient was considered to have a minimal effect because of low Reynolds's number flow conditions. Following equation determines the moment experienced by the blade;

$$
M=\int_{r \operatorname{ros} 2}^{\operatorname{cts}} \frac{\rho}{2} \in V_{0}^{2} \alpha\left(C_{M}\right) d A
$$

\section{Power}

With the aerodynamic parameters known, the next step was to find out the total power generated by the blade. Equation 10 suggests that in order to figure out the power generated by the blade, toque, $Q$, needs to be determined which can be described as follows; 


$$
Q=\int_{\text {root }}^{\text {th }} r \frac{\rho}{2} c V_{0}^{2}\left(C_{L} \cos \Phi-C_{D} \sin \Phi\right) d r
$$

The equation yields result for the torque produced by the blade. Since power is a product of torque and angular speed, iterations with respect to the tip speed and free stream wind, were conducted. The iterations resulted in an average value for the angular speed which was then used to determine power. It was also desired to determine the electrical power output to compare the design with other competitors. For that purpose, it was assumed that one-third power is lost in the process of converting from mechanical to electrical power.

\subsection{Results}

Once the governing equations were found, calculated values determined the blade geometry, shown in Table 2 . Once the blade geometry was finalized, analysis conducted on the turbine blade yielded results that are tabulated in Table 3. Although equations were used with some approximations, it was ascertained to yield a conservative result.

Table 2: Blade geometry values

\begin{tabular}{|c|c|}
\hline Parameter & $\begin{array}{l}\text { Value } \\
\end{array}$ \\
\hline Root Airfoil & NACA $63-425$ \\
\hline Tip Airfoil & NACA $63-415$ \\
\hline Aspect Ratio- $A R$ & 9.14 \\
\hline Solidity $-\sigma$ & 0.1 \\
\hline Span-b & $1.52[\mathrm{~m}]$ \\
\hline Planform Area $-S$ & $0.251\left[\mathrm{~m}^{2}\right]$ \\
\hline Taper Ratio $-\lambda$ & 0.23 \\
\hline Blade Twist Difference $-\Delta \beta$ & 20 [deg] \\
\hline Root Chord - $c_{\text {root }}$ & $0.27[\mathrm{~m}]$ \\
\hline Tip Chord - $c_{\text {tip }}$ & $0.06[\mathrm{~m}]$ \\
\hline Rotor Area - A & $7.54\left[\mathrm{~m}^{2}\right]$ \\
\hline 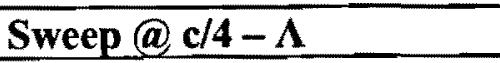 & $-4[\mathrm{deg}]$ \\
\hline Angle of Attack - $\alpha$ & $7[\mathrm{deg}]$ \\
\hline
\end{tabular}


Table 3: The table shows the result of blade analysis

\begin{tabular}{|l|c|}
\hline \multicolumn{1}{|c|}{ Parameter } & Value \\
\hline Free-stream Velocity $-\mathbf{V}_{\mathbf{0}}$ & $4[\mathrm{~m} / \mathrm{s}]$ \\
\hline Density - $\mathbf{p}$ & $1.229\left[\mathrm{~kg} / \mathrm{m}^{3}\right]$ \\
\hline Lift Coefficient $-\mathbf{C}_{\mathbf{L}}$ & 1.3 \\
\hline Drag Coefficient $-\mathbf{C}_{\mathbf{D}}$ & 0.174 \\
\hline Moment Coefficient $-\mathbf{C}_{\mathbf{M}}$ & -0.127 \\
\hline Lift - L & $830[\mathrm{~N}]$ \\
\hline Drag - D & $112[\mathrm{~N}]$ \\
\hline Moment - M & $-0.1[\mathrm{~N} \cdot \mathrm{m}]$ \\
\hline Torque - Q & $126[\mathrm{~N} \cdot \mathrm{m}]$ \\
\hline 3-blade Power - P & $665[\mathrm{~W}]$ \\
\hline 3-blade Electrical Power $-\mathbf{P}_{\text {ele }}$ & $465[\mathrm{~W}]$ \\
\hline
\end{tabular}




\section{Chapter 4: Structures}

\subsection{Material}

In order to keep the start-up speed low, it was required to keep the weight of the blade as low as possible. To achieve that, it was desired to use light weight material with high strength. Metals were deemed inefficient for the design as they have a very high potential to interfere with radio and television reception [1].

With the above described requirements, composites were studied because of their high strength to weight ratios and transparency to electromagnetic waves. Material strength, weight and cost were simultaneously analysed to get an inexpensive, high performance blade. The proposed deign called for polystyrene core with E-fibreglass-epoxy skin for strength. Fibreglass was chosen over carbon-fibre because of its low cost. Polystyrene core is easy to manufacture for the desired shape while E-fibreglass-epoxy provides the required strength. Some structural properties of E-fibreglass-epoxy are listed in Table 4.

Table 4: Typical properties of E-fibreglass-epoxy at room temperature [6]

\begin{tabular}{|l|c|}
\hline \multicolumn{1}{|c|}{ Property } & Values \\
\hline Density & $1950\left[\mathrm{~kg} / \mathrm{m}^{3}\right]$ \\
\hline Poisson Ratio & 0.22 \\
\hline Ultimate Tensile Stress - Longitudinal & $724[\mathrm{MPa}]$ \\
\hline Ultimate Tensile Stress - Transverse & $70.3[\mathrm{MPa}]$ \\
\hline Ultimate Compressive Stress - Longitudinal & $476[\mathrm{MPa}]$ \\
\hline Ultimate Compressive Stress - Transverse & $227[\mathrm{MPa}]$ \\
\hline Young's Modulus - Longitudinal & $29[\mathrm{GPa}]$ \\
\hline Young's Modulus - Transverse & $12.6[\mathrm{GPa}]$ \\
\hline Shear Modulus & $3.5[\mathrm{GPa}]$ \\
\hline
\end{tabular}




\subsection{Stress Analysis}

Stress analysis was conducted on the turbine blade to determine the structural design for the most favourable performance. It was assumed that the polystyrene core would provide very little strength hence it was excluded from the test. In order to keep the weight and manufacturing cost of the blade as low as possible, it was required to keep the outer layer thickness to a minimum. The test was conducted to find the thickness value that would give blade the desired strength yet make it light enough to start under low wind speeds.

For the analysis, ANSYS ${ }^{\circledR}$ [14] software was used to determine the optimal thickness for the Efibreglass-epoxy layer. Appendix B provides the detailed stress analysis of the blade. Blade was tested with a single layer of E-fibreglass-epoxy aligned longitudinally along the span. It is worth noting that unlike the wing of an aircraft under cruise condition, only a fraction of lift causes the bending to the blade since most of the force is converted into torque. Using the loads calculated in the Blade Analysis section, shown in Table 3, the design was tested for bending and torsion. In order to get a conservative design, and to ensure reliability and durability under strong wind conditions, the blade was tested for the total lift force.

Once a design was achieved to sustain bending stress, the blade was tested under torsion for optimal design. The design was analysed after bending stress test successfully sustained the torsion caused by the bending moment. The results from the test are tabulated below in Table 5;

Table 5: Test results of stress analysis on the designed turbine blade

\begin{tabular}{|l|l|}
\hline Maximum Stress & $50[\mathrm{MPa}]$ \\
\hline Safety Factor & 6 \\
\hline Maximum Deflection & $0.15[\mathrm{~m}]$ \\
\hline Thickness & $2.5[\mathrm{~mm}]$ \\
\hline Layers & Single Layer \\
\hline Total Weight & $63[\mathrm{~N}]$ \\
\hline Start-up Speed & $2[\mathrm{~m} / \mathrm{s}]$ \\
\hline
\end{tabular}


The maximum stress experienced by the blade is significantly below the ultimate stress limit of E-fibreglass-epoxy. Blade design and the material used were found to be of high strength. Even while having the lowest possible thickness, a safety factor of 6 existed. The thickness cannot be further reduced as the above conditions were yielded with the single fibreglass layer.

\subsection{Manufacturing}

Manufacturing plays a vital role in determining the feasibility of the design and the product's overall cost. In order to manufacture the desired blade design, many different structural designs were considered based on their manufacturability. The goal was to have a design such that most of the manufacturing can be done by hand. It was desired to have an easy to manufacture design with minimal parts. Limiting the number of parts reduce the overall cost by minimizing the labour and material cost. Keeping the above described requirements in mind, couple of manufacturing procedure were suggested to manufacture the blade with least amount of manhours.

\subsubsection{Procedure - Cutting}

1. Using the hotwire, cut the appropriate shape of the blade

a. Starting with $1.5[\mathrm{~m}]$ long, $0.3[\mathrm{~m}]$ wide polystyrene slab.

b. Outline the wing-root cross-section on one side while outline the wing-tip cross-section on the other with appropriate angle to each other.

c. Manual cutting operation can be conducted with carefully matching the speeds relatively.

2. Apply the layer of fibreglass in the longitudinal direction.

3. Apply epoxy to bind the fibreglass to the foam.

\subsubsection{Procedure - Moulding}

1. Get the blade shape out of a mould for the specified dimensions. It is done to create the geometry of the blade which gives a solid blade.

2. Apply the layer of fibreglass in the longitudinal direction.

3. Apply epoxy to bind the fibreglass to the foam. 


\section{Chapter 5: Conclusion}

\subsection{Discussion}

The designed blade had better performance than the one used as a benchmark, Whisper 200[9]. Table 6 shows the performance comparison between the two designs.

Table 6: Table shows the comparison between the designed model and the traditional turbine

\begin{tabular}{|l|l|l|}
\hline Specification & With designed blade & Traditional Whisper 200 \\
\hline Electrical Power at $4[\mathrm{~m} / \mathrm{s}]$ wind & $465[\mathrm{~W}]$ & $180[\mathrm{~W}]$ \\
\hline Start-Up Speed & $2[\mathrm{~m} / \mathrm{s}]$ & $3.1[\mathrm{~m} / \mathrm{s}]$ \\
\hline Blade Span & $1.5[\mathrm{~m}]$ & $1.35[\mathrm{~m}]$ \\
\hline
\end{tabular}

The above table shows that the designed blade, when used with an efficient electrical generator, can produce more than 180 [W] of power. It was also recognized that the designed turbine blade can start at wind speed lower than $3.1[\mathrm{~m} / \mathrm{s}]$. It can be safely established that the designed blade has a better performance than the one being used by Whisper 200[9].

There are multiple reasons for having better performance than the traditional Whisper 200[9] blade. The designed blade uses advanced NACA 6-series airfoil that enables the blade to have a high lift-to-drag ratio. On the other hand, the traditional Whisper blade is a plate at a finite angle of attack generating torque by changing the direction of the flow. It causes more drag and produces less rotation as compared to reaction turbine, where pressure difference generates the lift. Because of higher torque, total power output of the designed blade is greater than Whisper 200[9].

Start-up speed is directly dependent on the weight of the blade and the lift being generated. The designed turbine blade is a sandwich structure of polystyrene core with E-fibreglass-epoxy whereas the traditional Whisper blades are made up of carbon reinforced fibreglass [9], making Whisper blades heavier than the designed blade. Since traditional Whisper blades generate less lift and are made up of heavier material, they have a higher start-up speed. 
Although the designed blade proved to be more efficient then the existing small wind turbine blades, it can be further improved. The blade has a safety factor of 6 which suggests that blade is structurally strong enough to safely sustain more load. Improvements can be made in the blade design by increasing the tip chord which would produce more torque and consecutively more power. Another improvement could be the use of a different material for the outer layer. An inexpensive low strength fibre can also be used for the same blade geometry to decrease the overall cost.

\subsection{Concluding Remarks}

The aim of this project was to determine if a better blade design can be achieved to improve the performance of an existing small wind turbine. Using Whisper 200[9] wind turbine as a reference, it was concluded that improvements can be made on existing small turbines. The project was successful in presenting a blade design that not only is aerodynamically efficient but also easy to manufacture. Manufacturability was incorporated to have a design which can be mass produced at relatively low price. The project determined an improved blade design which yielded more power and lower start-up speed than the one used as a reference. 


\section{Appendix A: Aerodynamics}

\section{A1: Airfoil Selection}

First step to select an airfoil was to examine lift-drag ratios of different laminar flow airfoils. Figure 4 shows a comparison between 6 different airfoils compared for highest $L / D$ at standard operating condition. Figure 4 clearly shows that NACA $63-425$ has the highest overall $L / D$ ratio.

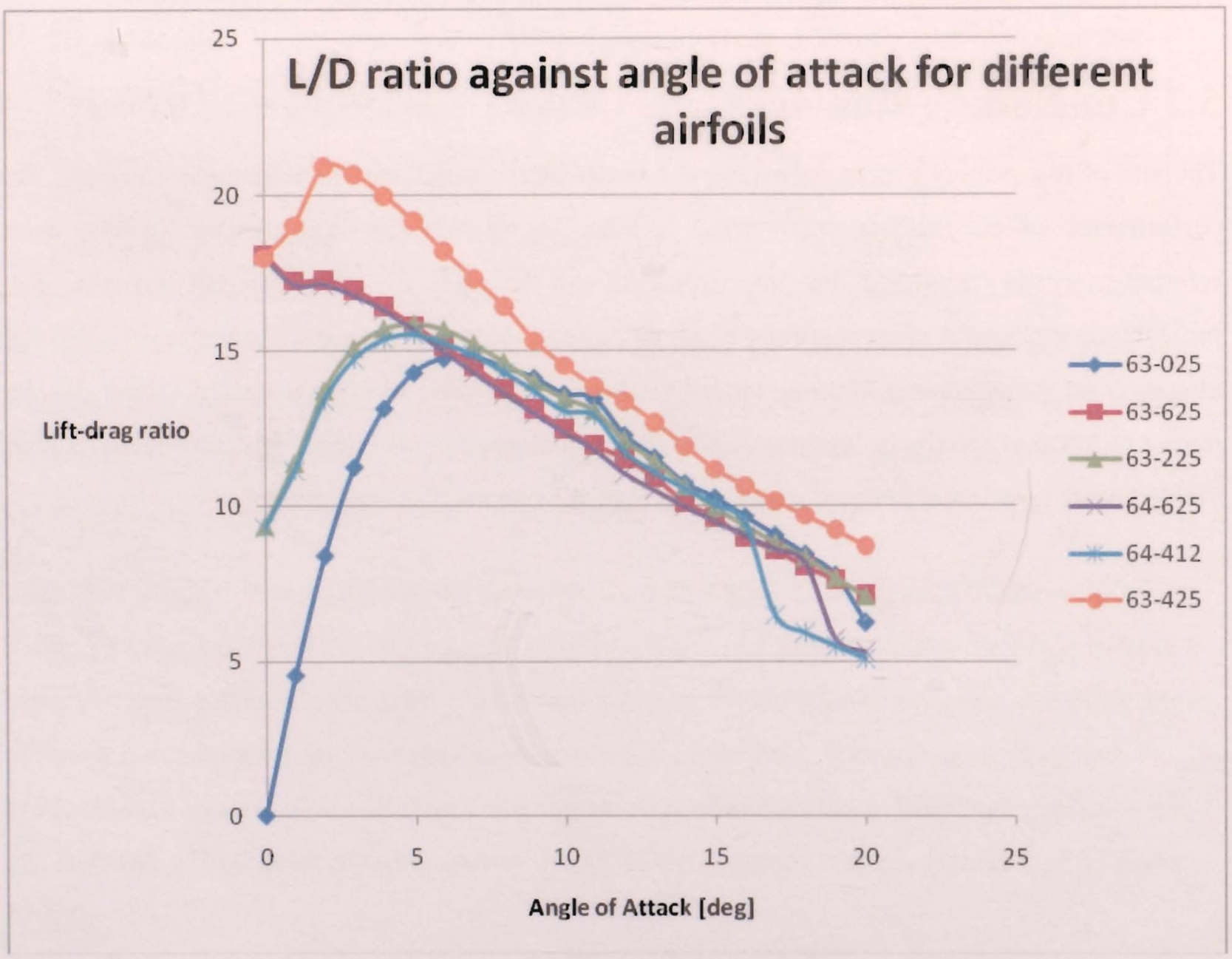

Figure 4: L/D ratio plotted against angle of attack for multiple airfoils.

Airfoil was not only selected on the bases of its $C_{\text {l,max }}$ and high $L / D$ ratio but also its characteristic of maintaining relatively high $C_{l}$ over a long range of wind speeds. Figure 5 shows the $L / D$ bucket of NACA 64-412 while Figure 6 indicates the $L / D$ for NACA $63-425$ airfoil. 


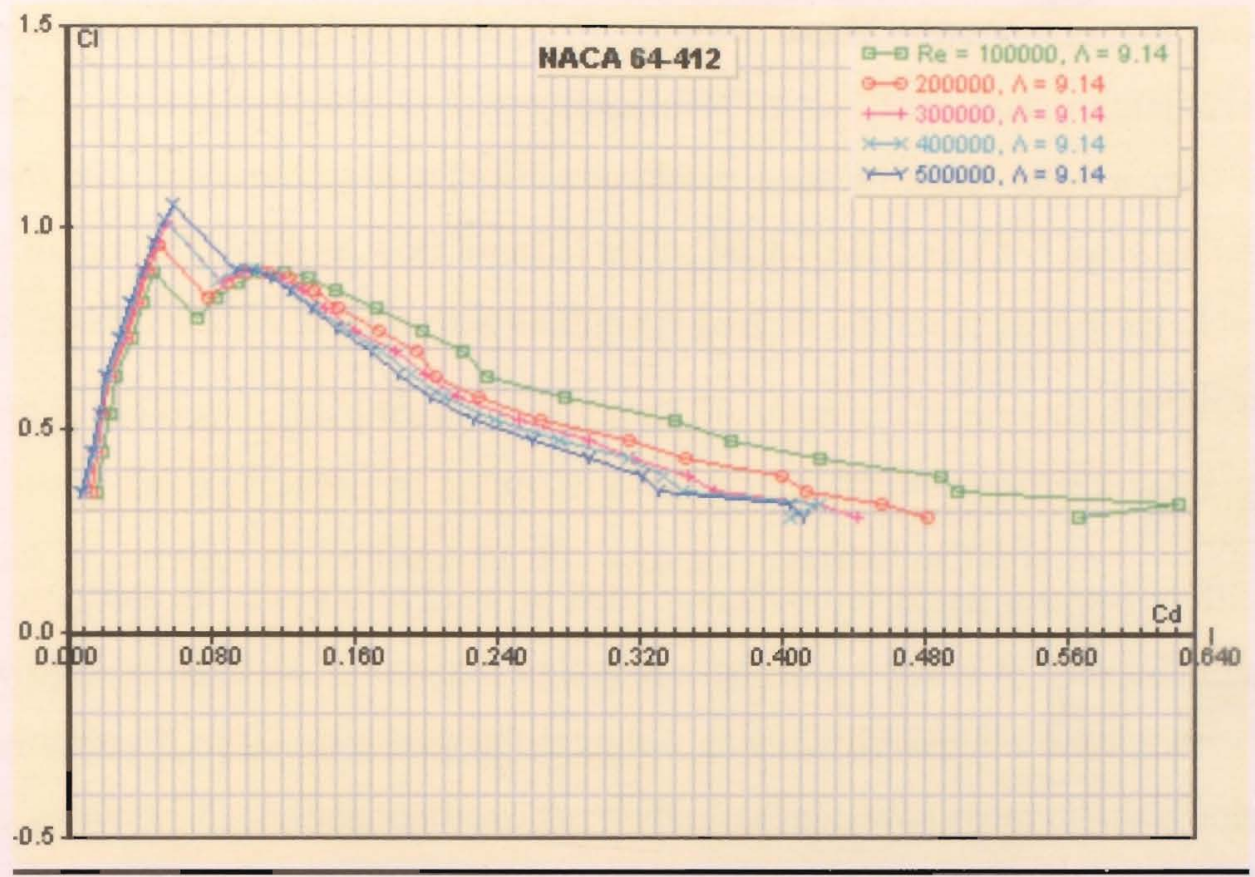

Figure 5: $L / D$ bucket of NACA 64-412 airfoil for multiple Revnolds's number.

NACA 64-412, in Figure 5, has a maximum $C_{l}$ value of just above one. It can also be seen from Figure 5 that the lift coefficient fluctuated violently, initially, and then decreases sharply with the increase in drag coefficient. This fluctuation and sudden drop in lift is undesirable as it would disable the blade to operate over a variable range of wind speeds and angle of attack.

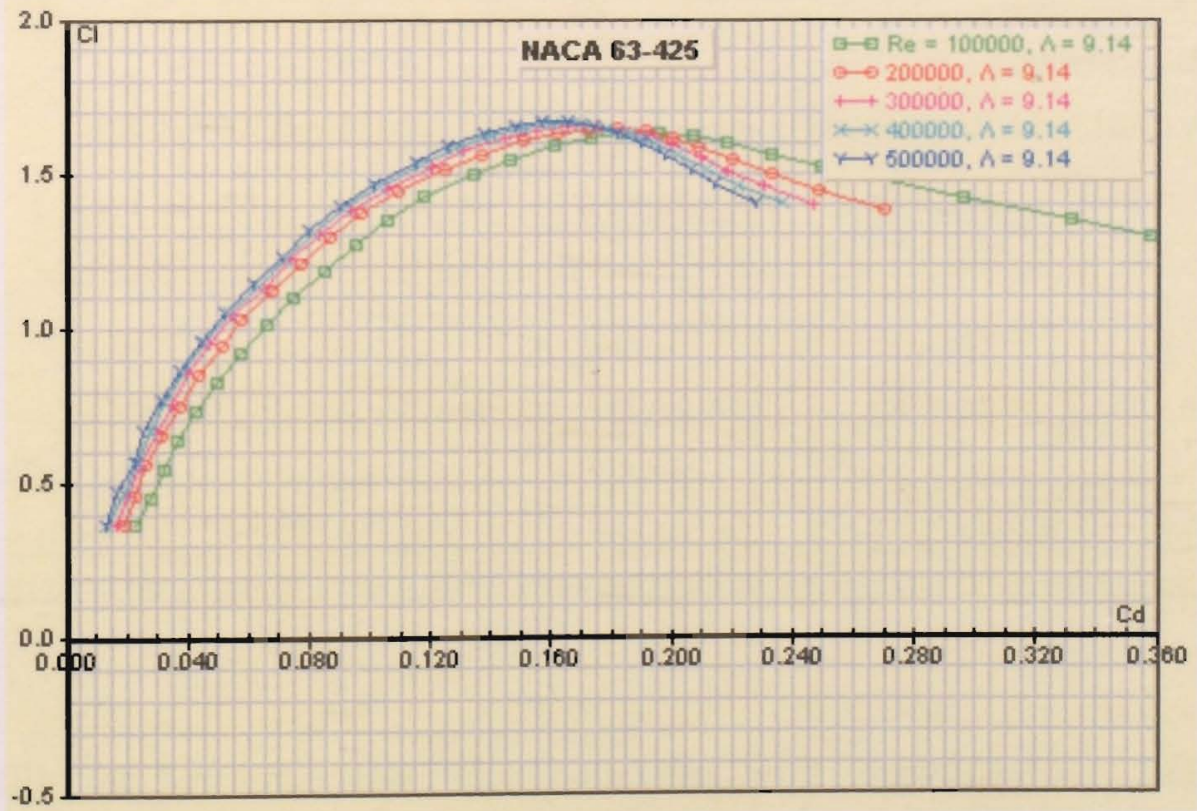

Figure 6: $L / D$ bucket of NACA 63-425 airfoil for multiple Revnolds's number. 
Figure 6 shows that NACA $63-425$ has a higher $C_{l, \max }$ and a wider $L / D$ bucket as compared to NACA 64-412. High maximum lift coefficient and large $L / D$ bucket ensures high aerodynamic performance over a wide range of wind conditions. Similar procedure was also carried out to compare existing NACA 63 and NACA 64 series laminar flow airfoils. The airfoil that had the most favourable performance for the desired conditions and requirements was NACA 63-425, as mentioned before.

\section{Blade Tip Airfoil}

One of the safety features needs to be incorporated in wind turbines is its ability to not exceed certain rotational speed. It is desired to have a design that would stall under high wind speed. High speed stall can be achieved by having a thin airfoil at the tip. Thin tip airfoil enables the flow separation point to move towards the leading edge as the wind speed increases, as shown in Figure 7. Lift decreases as the flow separation point marches forward, stalling the tip section of the blade.

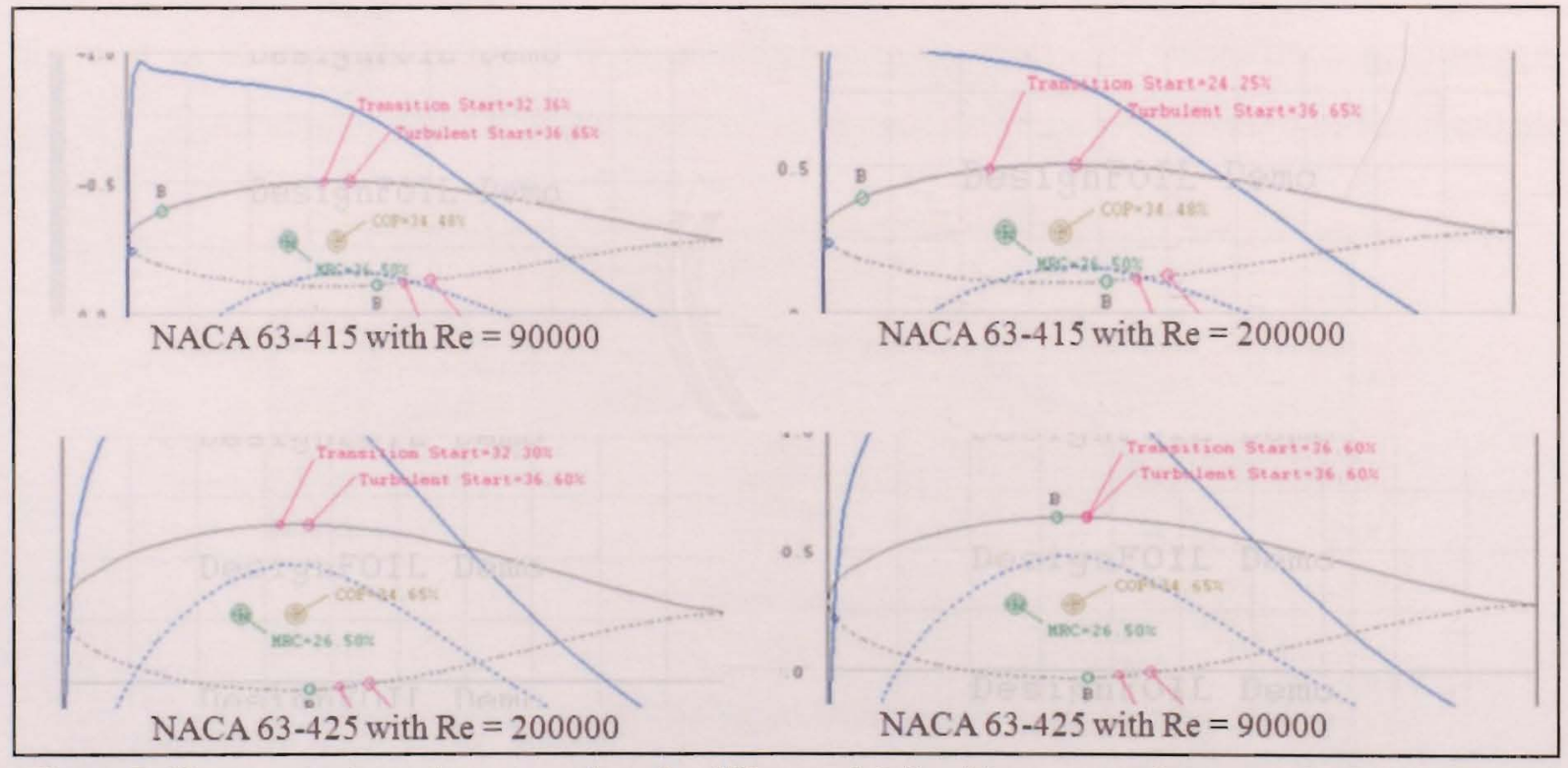

Figure 7: Flow separation point comparison for different airfoils with respect to increment in Revnolds's number.

Using JavaFOIL [16] software, flow separation point was compared for different airfoil thickness. The result concluded that for thinner airfoil, flow separation point moves faster 
towards the leading edge. For a very thin airfoil, low separation point moves towards the leading edge very fast, causing dynamic stress problems [10]. After considering the above mentioned considerations, NACA 63-415 was selected as a blade tip airfoil.

\section{A2: Blade Geometry}

Actuator disc is the disc formed by the rotation of the blades. The area of that disc was simply determined using the blade span as radius. For solidity, literature yielded a value of 0.1 for 3blade turbines. Values for solidity and the disc area are tabulated in Table 7.

Using this industry established value for solidity, planform area, $S$, was calculated through Equation 12. Once the planform area, $S$, is known, tip and root chord values were iterated for high aspect ratio. The iteration yielded root and tip chord values which were then used to determine taper ratio. Airfoil's percent thickness was used to get the root and tip section's thickness. The above described parameters are tabulated in Table 8 and Table 9 with the addition of taper ratio and quarter chord sweep.

Table 7: Values related to the rotor

\begin{tabular}{|c|c|}
\hline Area of Disc $\left[\mathrm{m}^{2}\right]$ & Solidity \\
\hline 7.54385 & 0.1 \\
\hline
\end{tabular}

Table 8: Airfoil section's geometric values

\begin{tabular}{|l|l|l|l|}
\hline Root chord & Tip chord & height-root & height-tip \\
\hline $0.27[\mathrm{~m}]$ & $0.0627[\mathrm{~m}]$ & $67.5[\mathrm{~mm}]$ & $15.67[\mathrm{~mm}]$ \\
\hline
\end{tabular}

Table 9: Table shows geometric values related to the turbine blade

\begin{tabular}{|l|l|l|l|l|}
\hline taper ratio & mean chord & $\mathbf{S}\left[\mathbf{m}^{\wedge} 2\right]$ & AR & Sweep @ $\mathbf{c} / 4$ \\
\hline 0.23 & $0.19[\mathrm{~m}]$ & 0.251461667 & 9.14 & $(-4 \mathrm{deg})$ \\
\hline
\end{tabular}




\section{Spanwise Chord}

Spanwise chord was calculated after determining the aspect ratio and the taper ratio of the blade.

As shown in Figure 8, spanwise chord values were determined using the equation of a line.

Tabulated values for spanwise chord are presented in Table 10.

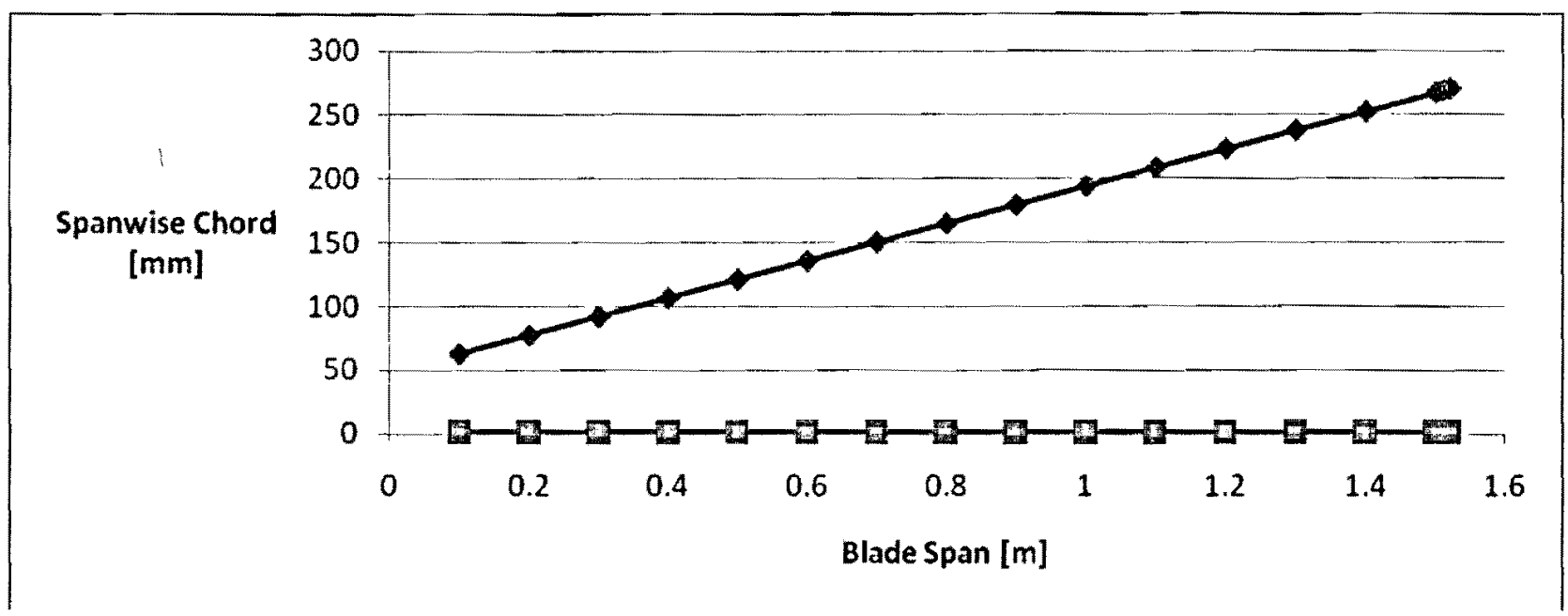

Fisure 8: Visual representation of chord values as it increases with the span

Table 10: Spanwise chord values

\begin{tabular}{|r|r|}
\hline \multicolumn{1}{|c|}{ Span [m] } & \multicolumn{1}{c|}{ Chord [m] } \\
\hline 0.1 & 0.06268 \\
\hline 0.3 & 0.09188 \\
\hline 0.5 & 0.12108 \\
\hline 0.7 & 0.15028 \\
\hline 0.9 & 0.17948 \\
\hline 1 & 0.19408 \\
\hline 1.2 & 0.22328 \\
\hline 1.4 & 0.25248 \\
\hline 1.5 & 0.26708 \\
\hline 1.52 & 0.27 \\
\hline
\end{tabular}




\section{A3: Blade Analysis}

\section{Lift}

Table 11 shows the spanwise lift distribution which was determined using Equation 16.

Table 11: Designed blade lift distribution with respect to span

\begin{tabular}{|r|r|r|r|c|c|c|}
\hline $\mathbf{r}[\mathbf{m}]$ & AOA & $\mathbf{C}_{\mathbf{L}}$ & $\mathbf{V}[\mathbf{m} / \mathbf{s}]$ & $\mathbf{c}[\mathbf{m}]$ & rho & $\mathbf{L}[\mathbf{N}]$ \\
\hline 0.1 & 7 & 1.2942 & 4 & 0.06268 & 1.225 & 5.564863282 \\
\hline 0.2 & 7 & 1.2942 & 4 & 0.07728 & 1.225 & 6.861082234 \\
\hline 0.3 & 7 & 1.2942 & 4 & 0.09188 & 1.225 & 8.157301186 \\
\hline 0.4 & 7 & 1.2942 & 4 & 0.10648 & 1.225 & 9.453520138 \\
\hline 0.5 & 7 & 1.2942 & 4 & 0.12108 & 1.225 & 10.74973909 \\
\hline 0.6 & 7 & 1.2942 & 4 & 0.13568 & 1.225 & 12.04595804 \\
\hline 0.7 & 7 & 1.2942 & 4 & 0.15028 & 1.225 & 13.34217699 \\
\hline 0.8 & 7 & 1.2942 & 4 & 0.16488 & 1.225 & 14.63839595 \\
\hline 0.9 & 7 & 1.2942 & 4 & 0.17948 & 1.225 & 15.9346149 \\
\hline 1 & 7 & 1.2942 & 4 & 0.19408 & 1.225 & 17.23083385 \\
\hline 1.1 & 7 & 1.2942 & 4 & 0.20868 & 1.225 & 18.5270528 \\
\hline 1.2 & 7 & 1.2942 & 4 & 0.22328 & 1.225 & 19.82327175 \\
\hline 1.3 & 7 & 1.2942 & 4 & 0.23788 & 1.225 & 21.11949071 \\
\hline 1.4 & 7 & 1.2942 & 4 & 0.25248 & 1.225 & 22.41570966 \\
\hline 1.5 & 7 & 1.2942 & 4 & 0.26708 & 1.225 & 23.71192861 \\
\hline 1.51 & 7 & 1.2942 & 4 & 0.26854 & 1.225 & 23.8415505 \\
\hline 1.52 & 7 & 1.2942 & 4 & 0.27 & 1.225 & 23.9711724 \\
\hline
\end{tabular}

Lift values were plotted against span to yield the equation for the lift distribution, as shown in Figure 9, whereas Figure 10 shows the lift coefficient distribution for the turbine blade. The equation was integrated from root to tip to determine the total lift.

\section{Drag}

Using Equation 17(a), total drag was calculated using $e=0.83$. The equation determined the drag coefficient of the entire blade which was then used to determine spanwise drag distribution, tabulated in Table 12. The drag distribution was plotted along the span, in Figure 11, to determine the equation of the rag curve. The equation, shown in Figure 10, was integrated along the span to determine the total drag on the turbine blade. 


\section{Lift along the Span}

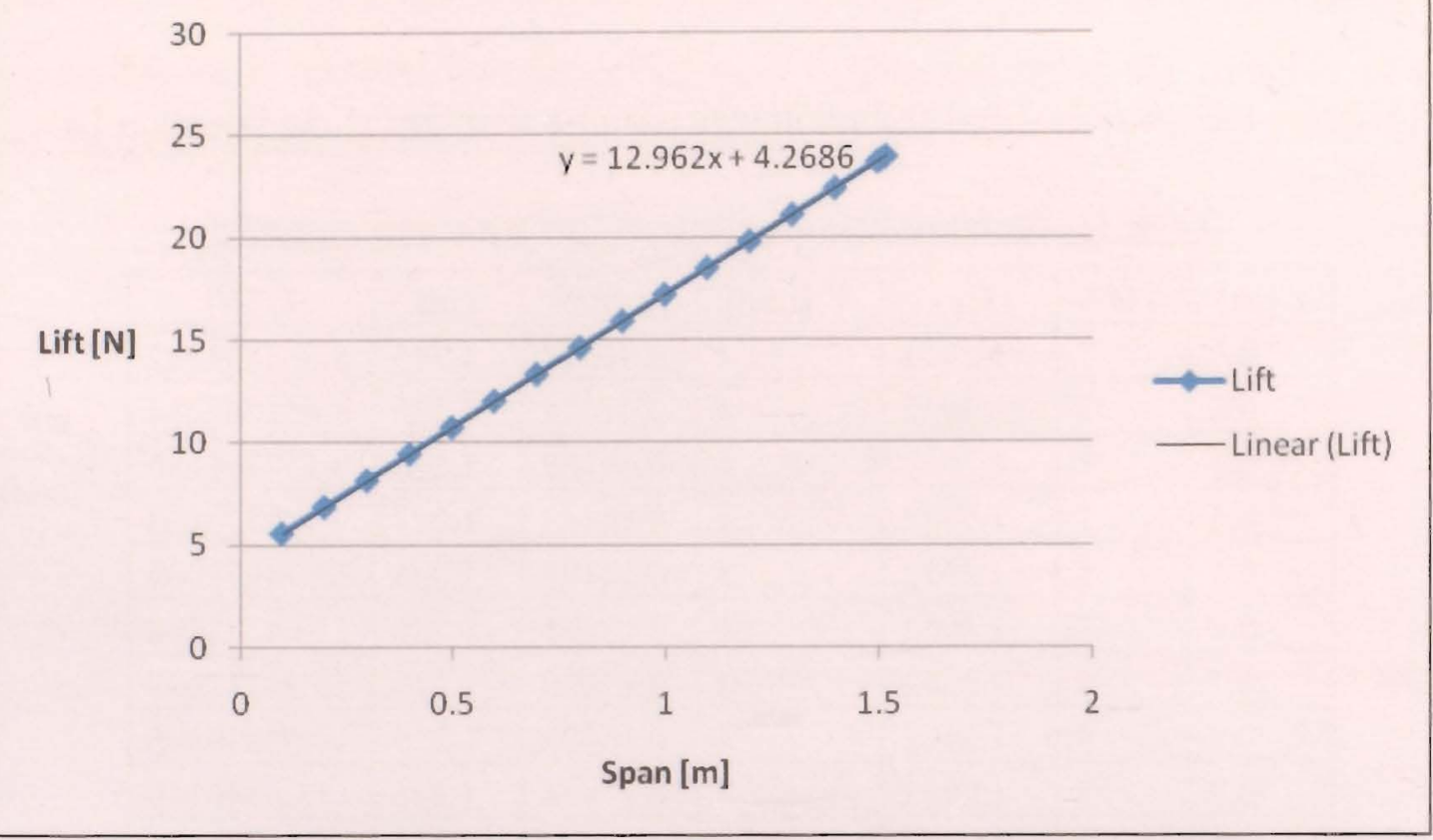

Figure 9: Spanwise lift distribution and the equation of the curve

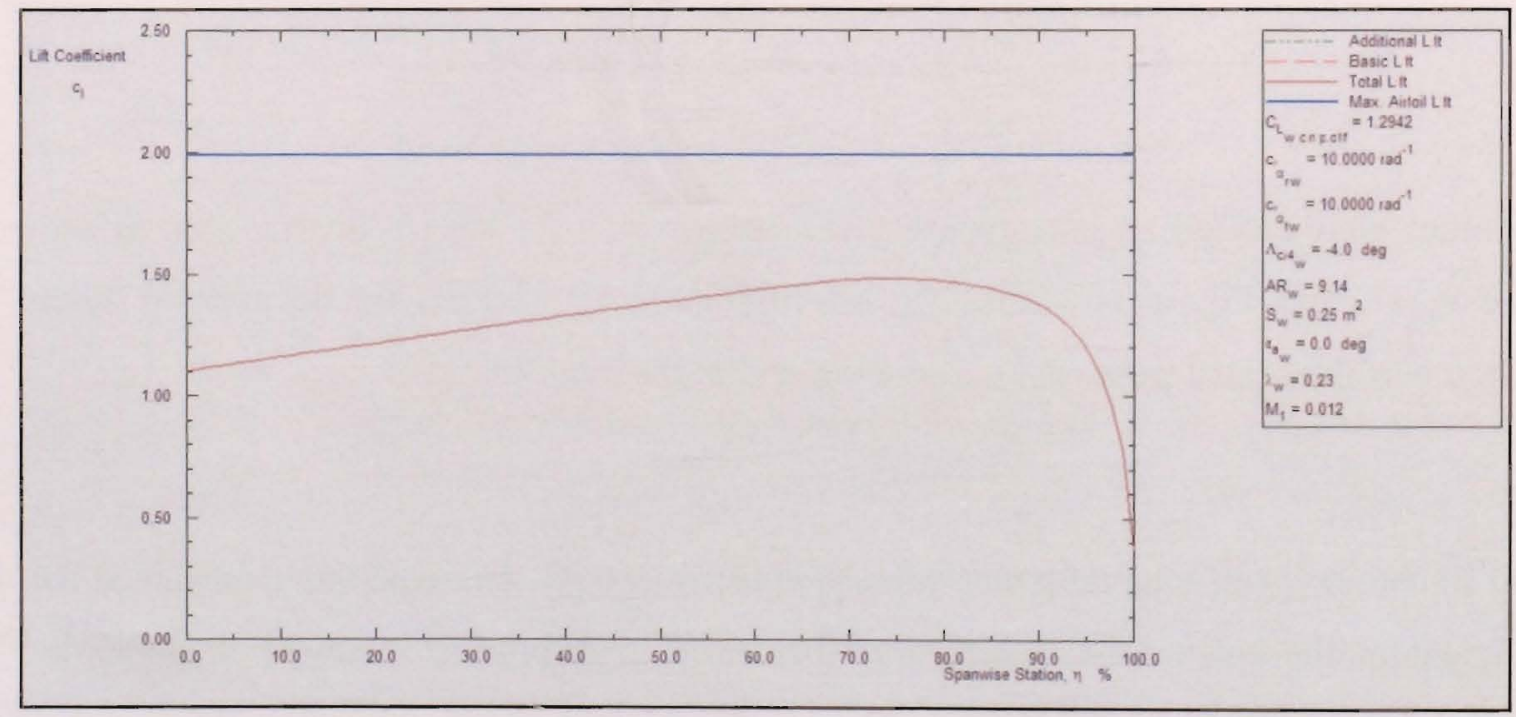

Figure 10: Lift coefficient distribution along the span of the designed blade 
Table 12: Drag distribution with respect to span

\begin{tabular}{|r|r|l|r|r|r|r|}
\hline $\mathbf{r}[\mathrm{m}]$ & $\mathbf{A O A}$ & $\mathbf{C}_{\mathbf{D}}$ & $\mathbf{V}[\mathrm{m} / \mathbf{s}]$ & $\mathbf{c}[\mathrm{m}]$ & $\mathbf{R h o}\left[\mathrm{kg} / \mathbf{m}^{3}\right]$ & $\mathbf{D}[\mathbf{N}]$ \\
\hline 0.1 & 7 & 0.174 & 4 & 0.06268 & 1.225 & 0.7481736 \\
\hline 0.2 & 7 & 0.174 & 4 & 0.07728 & 1.225 & 0.922445 \\
\hline 0.3 & 7 & 0.174 & 4 & 0.09188 & 1.225 & 1.0967164 \\
\hline 0.4 & 7 & 0.174 & 4 & 0.10648 & 1.225 & 1.2709879 \\
\hline 0.5 & 7 & 0.174 & 4 & 0.12108 & 1.225 & 1.4452593 \\
\hline 0.6 & 7 & 0.174 & 4 & 0.13568 & 1.225 & 1.6195308 \\
\hline 0.7 & 7 & 0.174 & 4 & 0.15028 & 1.225 & 1.7938022 \\
\hline 0.8 & 7 & 0.174 & 4 & 0.16488 & 1.225 & 1.9680736 \\
\hline 0.9 & 7 & 0.174 & 4 & 0.17948 & 1.225 & 2.1423451 \\
\hline 1 & 7 & 0.174 & 4 & 0.19408 & 1.225 & 2.3166165 \\
\hline 1.1 & 7 & 0.174 & 4 & 0.20868 & 1.225 & 2.490888 \\
\hline 1.2 & 7 & 0.174 & 4 & 0.22328 & 1.225 & 2.6651594 \\
\hline 1.3 & 7 & 0.174 & 4 & 0.23788 & 1.225 & 2.8394308 \\
\hline 1.4 & 7 & 0.174 & 4 & 0.25248 & 1.225 & 3.0137023 \\
\hline 1.5 & 7 & 0.174 & 4 & 0.26708 & 1.225 & 3.1879737 \\
\hline 1.51 & 7 & 0.174 & 4 & 0.26854 & 1.225 & 3.2054009 \\
\hline 1.52 & 7 & 0.174 & 4 & 0.27 & 1.225 & 3.222828 \\
\hline
\end{tabular}

Similar to lift distribution, drag was plotted against span and an equation was determines. The yielded equation was integrated along the span to determine the total drag.

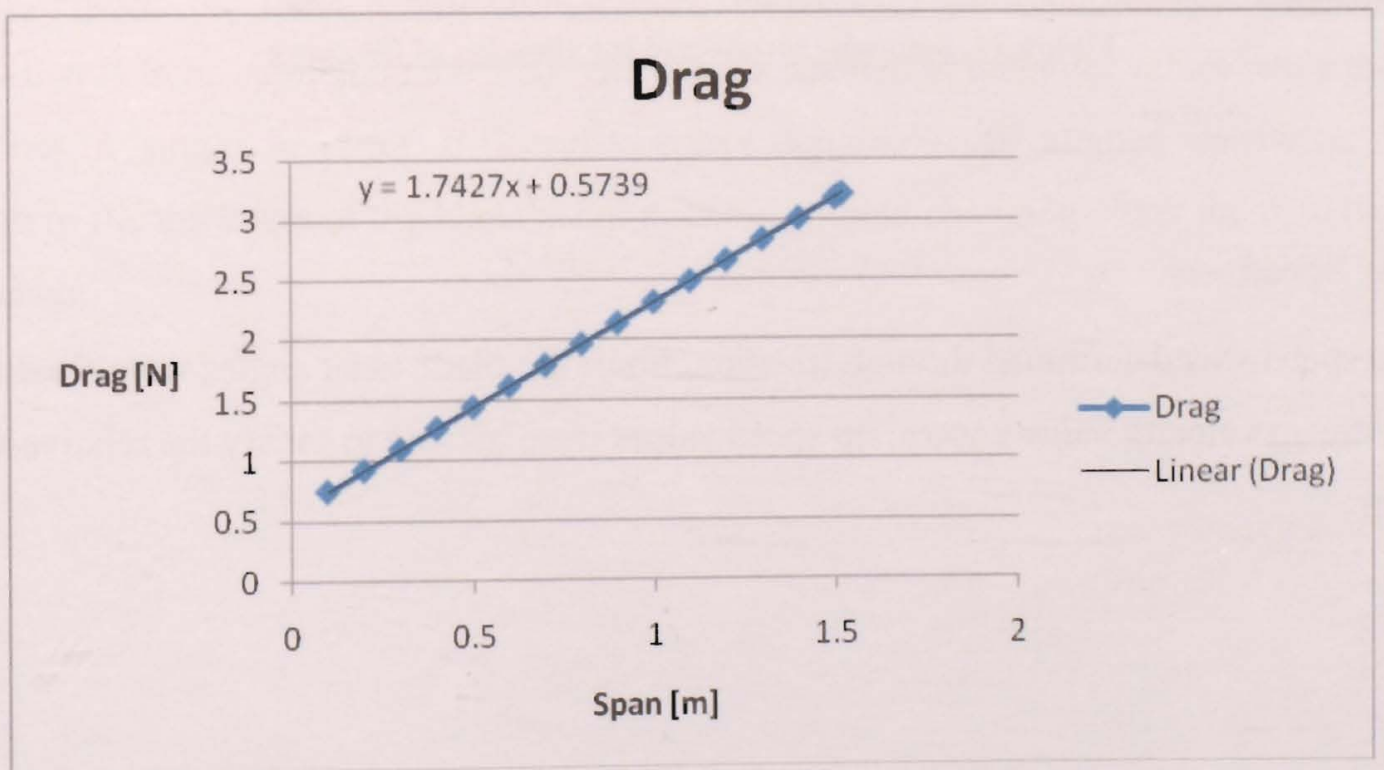

Figure 11: Spanwise drag distribution and the equation of the curve 


\section{Torque}

Using Equation 19, spanwise torque was plotted against span and the equation of the curve was determined as shown in Figure 12. The determined equation was integrated over the blade span to determine the total torque which was then used to calculate total power.

\section{Torque}

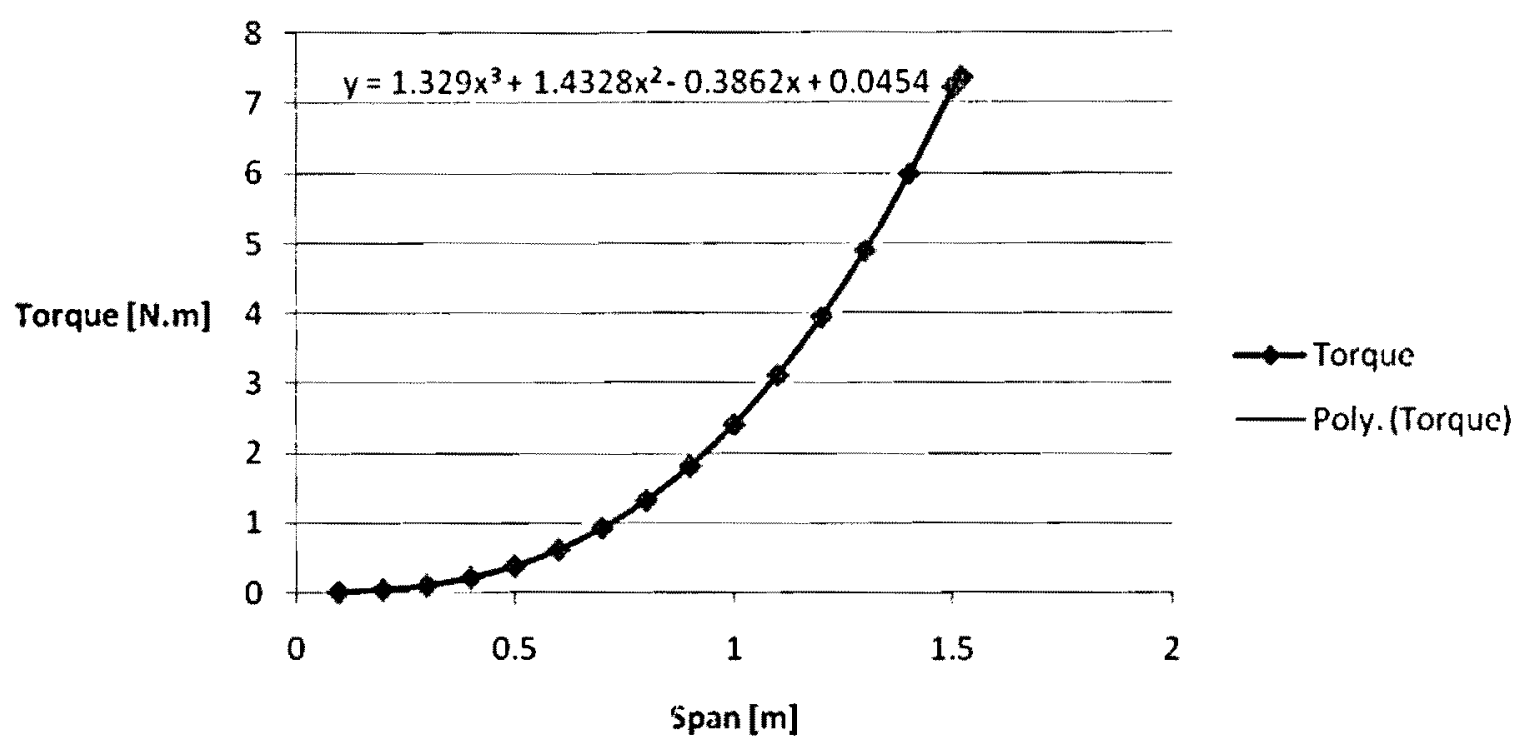

Figure 12: Spanwise torque and the equation of the curve

\section{Angular Speed - $\omega$}

Angular speed was determined through iteration. Since the blade twist angles were finalized and the freestream velocity value known, tip speed values were iterated to satisfy the relative velocity at the tip. 


\section{Appendix B: Structures}

In order to determine the most favourable thickness, hence the number of layers of E-fibreglassepoxy, structural analysis needed to be conducted on the designed blade. It was required to have a strong enough blade to sustain steady aerodynamic loads, namely lift and torque. ANSYS ${ }^{\circledR}$ [14] software was used to conduct structural testing for the blade. Four-noded, quadrilateral element, Shell 99, with six degrees of freedom per node, that deals with linear layered composite shell structures was used to determine the stress experienced by the blade.

Figure 13 shows the equivalent stress experienced by the blade. Loads were applied at the midspan and at the tip, simulating a spanwise distributed load, as listed in Table 11 and Table 12 for lift and drag, respectively. Lift load was applied in the positive-y direction while drag was applied in the negative-z direction with respect to the coordinates shown in Figure 13. Total moment value, as shown in Table 3, was applied at the tip. The moment was applied with a safety factor of 3 around $x$-axis. The application of total moment at the tip was done to test the blade for the extreme conditions and to have a conservative design.

The test concluded that the designed blade comprehensively sustained the expected loading. Although maximum stress experienced by the blade falls far below the ultimate stress value of $\mathrm{E}$ fibreglass-epoxy, the blade's structural design cannot be further optimized. The composite material that is to be applied on the blade can only be applied in quantum values while the tested design has a single layer of E-fibreglass-epoxy longitudinally aligned spanwise. Further reduction to the thickness of the blade is not possible without changing either the material or the blade design. 


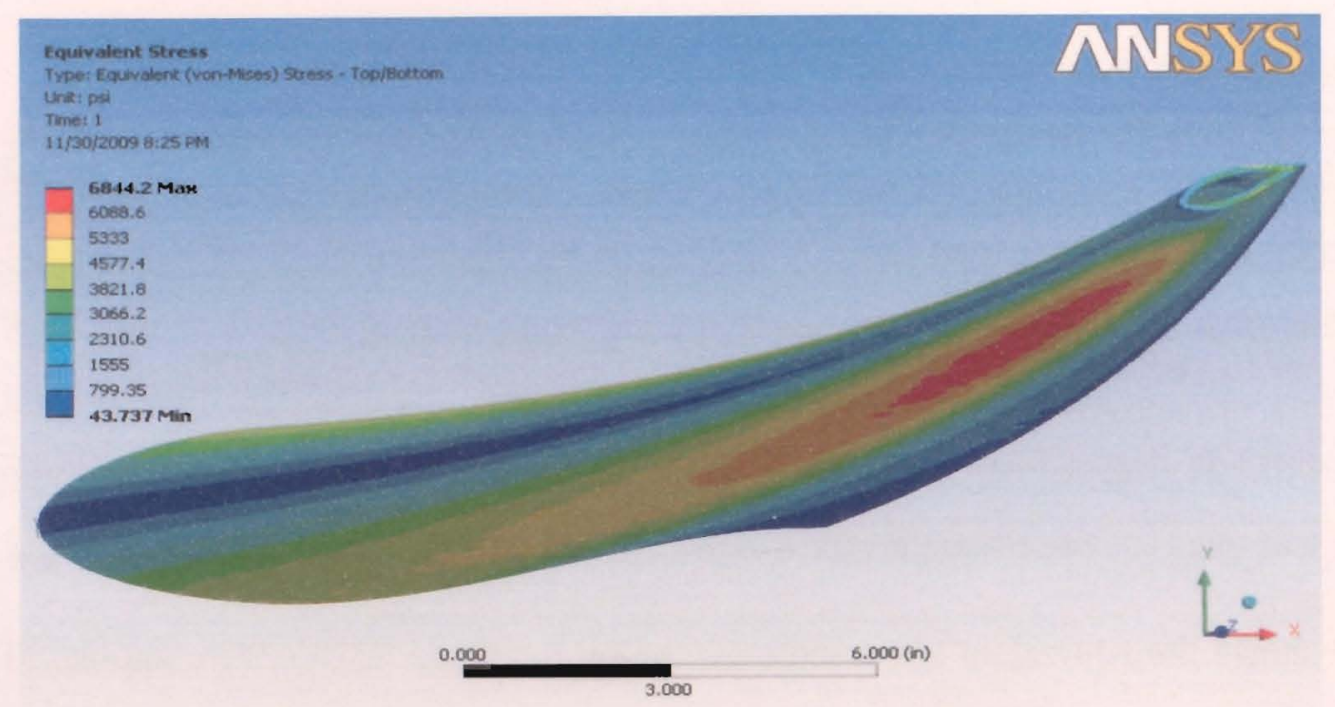

Figure 13: Blade loading test to determine equivalent stress for optimal thickness

Figure 14 shows the test result after applying total lift on the blade with single layer of Efibreglass-epoxy, where the maximum tip deflection value of $0.15[\mathrm{~m}]$ is depicted. The value is considered reasonable since any structure around the blade would be farther away.

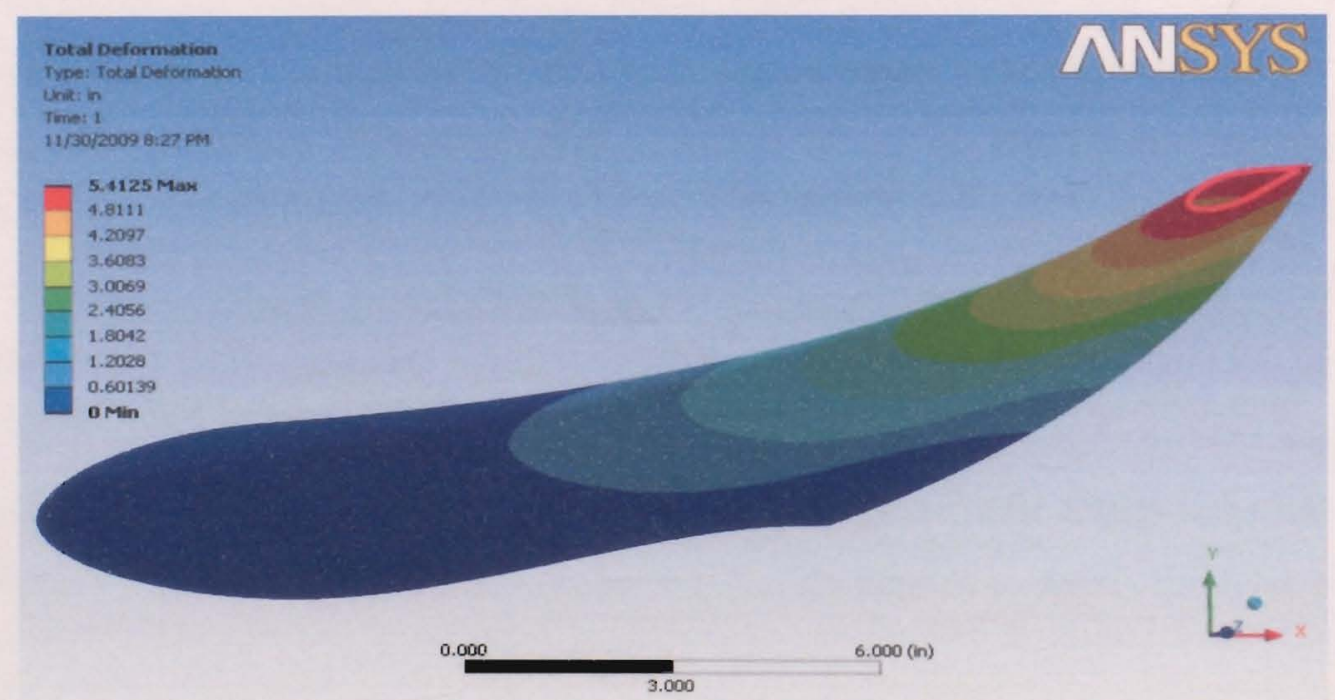

Figure 14: Blade bending test to determine maximum tip deflection 
Since the airfoil has a finite value of pitching moment, the blade experiences torsion. As shown in Figure 15, maximum deflection due to torsion is at the tip since the blade tip is free to move in any direction, unlike root which is clamped to the hub. Since the designed blade is to operate under extremely low subsonic speeds, the tip twist is almost negligible. Figure 14 and Figure 15 shows out of scale and exaggerated deflected shape. The total deflection due to torsion is small enough to be ignored.

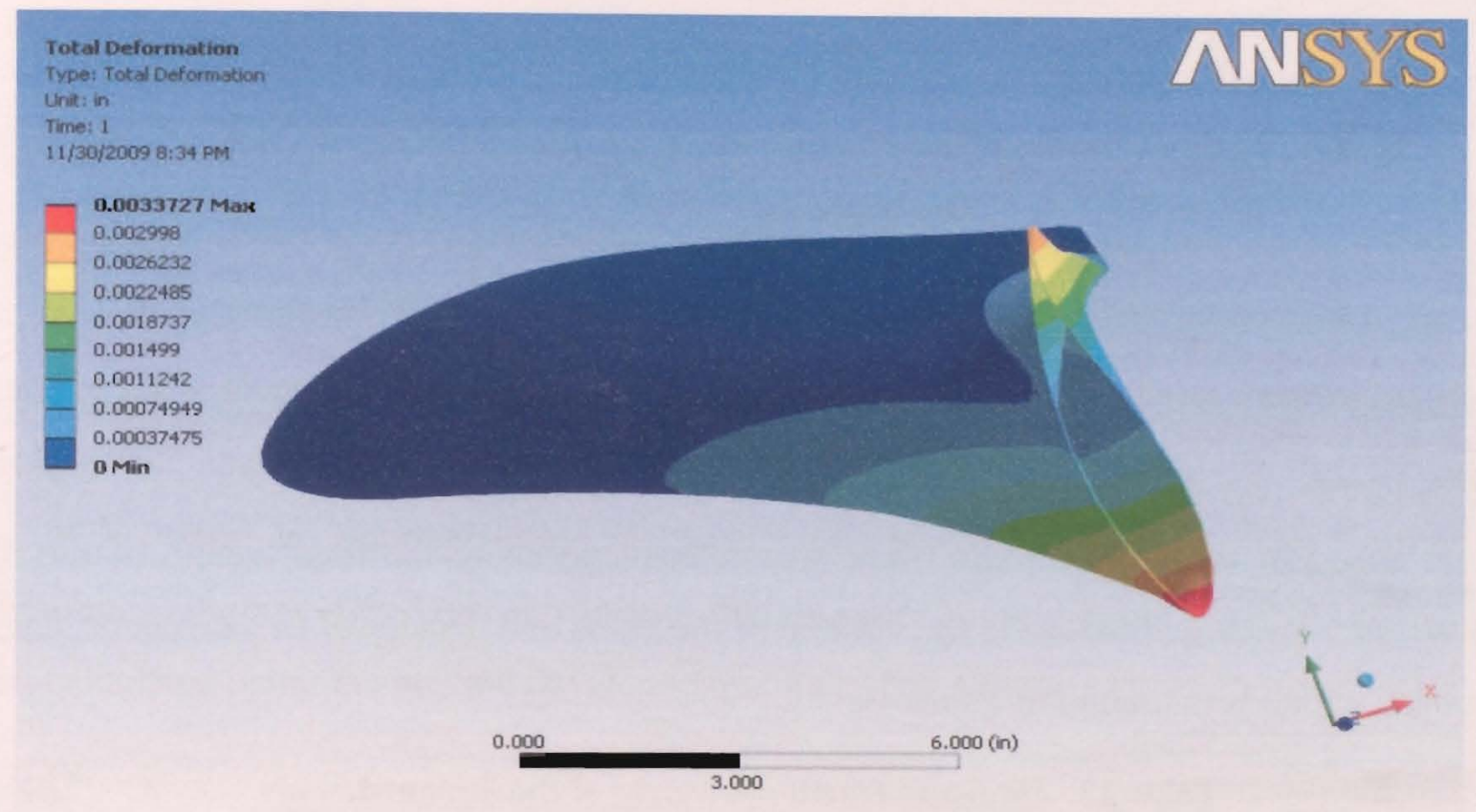

Figure 15: Torsion test to determine the maximum twist deflection

In figure 16, the blade is subjected to torque. The blade experiences maximum stress which is far below the ultimate stress limit of E-fibreglass-epoxy. The material's ability to sustain a lot more loading than it is designed for is an important aspect of wind turbine blade design. It is done to avoid structural failure during windy conditions. 


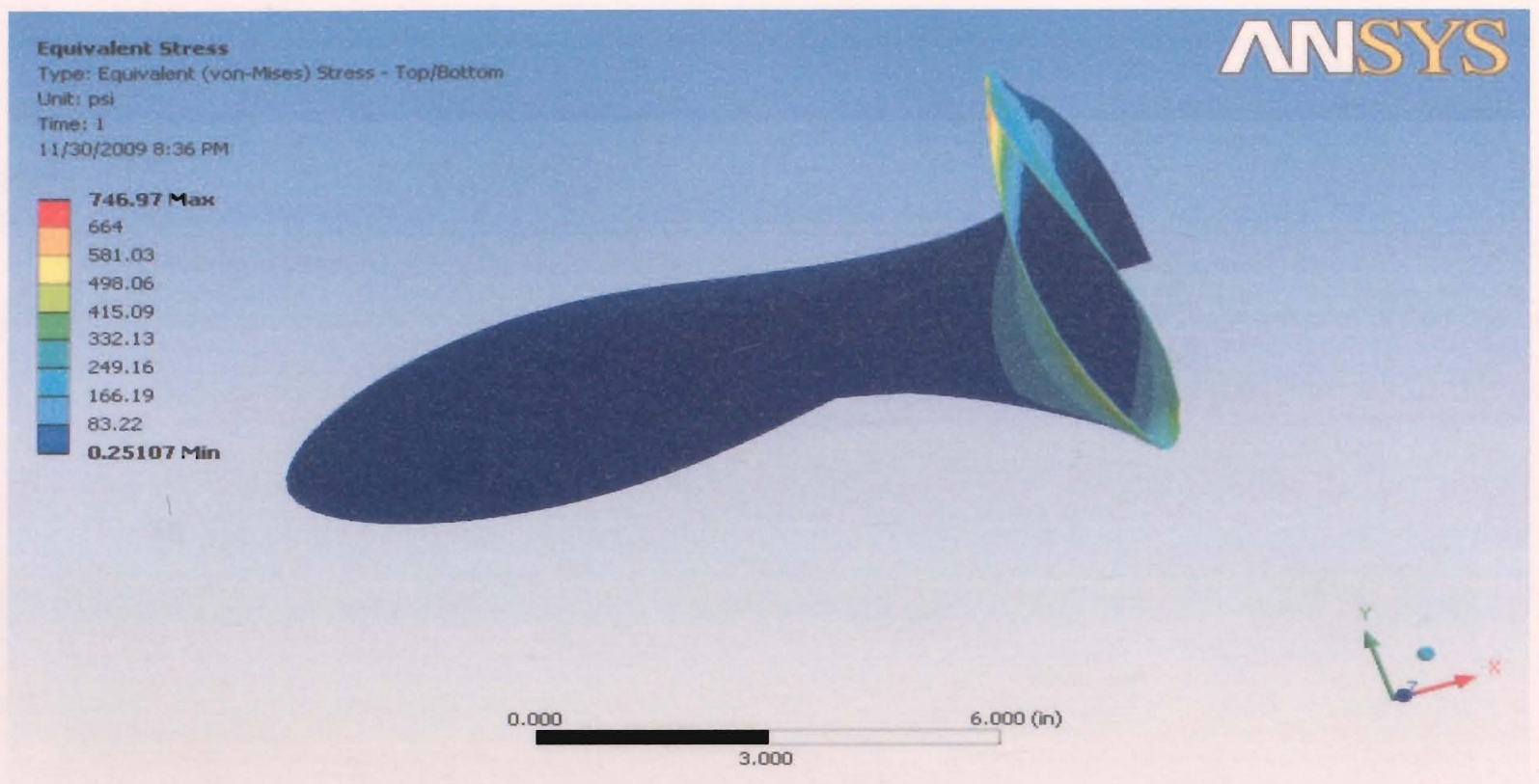

Figure 16: Blade's torsion test to determine if the maximum twist can be sustained

\section{B1: Start-up Speed}

Start-up speed of the wind turbine blade was determined using the total weight of the blade. Total weight was calculated using the volume of the blade and density of two different materials being used which is tabulated in Table 13.

Table 13: Total and fractional weight of the designed blade

\begin{tabular}{|l|c|c|}
\hline & weight [N] & volume $\left[\mathbf{m}^{3}\right]$ \\
\hline SKIN - E-fibreglass-epoxy & 23 & 0.001426 \\
\hline CORE- Polystyrene & 40 & 0.006 \\
\hline Entire Blade & 63 & 0.007426 \\
\hline
\end{tabular}

For the start-up speed calculation, it is considered that the blade is at rest, i.e., not rotating. Because of non-rotating blade approximation, most of the blade would be stalled except for the section near the root. Looking at the blade twist angles and comparing it to lift curve slopes, the stalled section of the blade was estimated. Using the lift equation, different wind speed values were used to determine lift for the section of the blade that is closer to the root. The wind speed for which the total lift value corresponded with the blade weight value was determined to be the start-up speed. 


\title{
Appendix D: Descriptions
}

\section{JavaFoil}

JavaFoil [16] is basic software, written in C-language, which uses several traditional methods for airfoil analysis. For the software, potential flow analysis is done with a higher order panel method (linear varying vorticity distribution). Taking a set of airfoil coordinates; the software calculates the local, inviscid flow velocity along the surface of the airfoil for any desired angle of attack.

\section{DesignFoil}

DesignFoil [15] is software that analyses the airfoil. It uses the panel method to panelize the airfoil to determine the surface velocities. Once the velocities are known, the software calculates the surface pressure coefficient. Given a velocity distribution, one can use an integral method for predicting the shape of the boundary layer profile at various stations along the airfoil. DesignFOIL uses an incompressible approximation method based on von Karman and Pohlhausen. With boundary layer thicknesses known near the trailing edge, the drag coefficient is then calculated using the method developed by Squire and Young.

\begin{abstract}
ANSYS $^{\circledR}$
ANSYS $^{\circledR}[14]$ is a general-purpose finite element analysis software. The software numerically solves mechanical problems, including static/dynamic structural analysis (both linear and nonlinear), heat transfer and fluid problems, as well as acoustic and electro-magnetic problems.
\end{abstract}

\section{NACA 6-series airfoils}

NACA, predecessor of NASA, came up with a system to describe the airfoil shape which is mathematically derived from the desired lift characteristics. The 6-series airfoils were designed with emphasis on maximizing laminar flow and are described by five digits. First digit indicates the series name, which is always number- 6 for this series. Second digit describes the distance of the minimum pressure area in tens of percent of chord followed by a hyphen. Next digit describes the lift coefficient in tenths. Last two digits represent the maximum thickness in 
percent of chord. So the airfoil used for the blade hub is NACA $63-425$ which means that it is a 6-series airfoil that has minimum pressure $30 \%$ chord-length back with a lift coefficient of 0.4 and maximum thickness of $25 \%$ of the chord. As a comparison, airfoil used for the blade tip, NACA $63-415$, has a maximum thickness of $15 \%$ chord length as compared to $25 \%$ for the hub section. 


\section{References}

1 Clarke, S. (2003, September ). Electricity Generation Using Small Wind Turbines at Your Home or Farm. Retrieved October 2009, from Ministry of Agriculture, Food and Rural Affairs of Ontario: http://www.omafra.gov.on.ca/english/engineer/facts/03047.htm\#neighbourly

2 Darling., D. (n.d.). Horizontal-axis wind turbine (HAWT). Retrieved 2009, from The Encyclopedia of Alternative Energy and Sustainable Living: http://www.daviddarling.info/encyclopedia/H/AE_horizontal-axis_wind_turbine.html

3 Flack, R. D. (2005). Fundamentals of jet propulsion with applications. Series: Cambridge Aerospace Series (No. 17), Cambridge: Cambridge University Press.

4 Hansen, M. O. L. (2008). Aerodynamics of Wind Turbines. London: James \& James.

5 Hau, E. (2006). Wind turbines: fundamentals, technologies, application, economics. Birlin: Springer (Translated by von Renouard H.).

6 Raymer, D. (1999). Aircraft Design: A Conceptual Approach. Ohio, U.S.A: AIAA.

7 Smith, R. (2007). Anatomy of a Horizontal-Axis Wind Turbine. Retrieved 2009, from Symscape: http://www.symscape.com/blog/anatomy_horizontal_wind_turbine

8 Southwest Windpower. (n.d.). Whisper 100/200. Flagstaff, Arizona, U.S.A: Southwest Windpower. 
9 van Rooij, R. and Timmer, D. (2006). Design of Airfoils for Wind Turbine Blades. Delf:

T.U.Delf. Retrieved January 27, 2010, from

http://rukautestu.vin.bg.ac.yu/energija/presentations/SixBestPosters/V.PAREZANOVIC.ppt

10 Burton, T. et al. (2004). Wind Energy: Handbook. Sussex: Wiley.

11 Weather for Toronto, Ontario: Last Year. (n.d.). Retrieved September 4, 2009, from Canada Weather Statistics: http://toronto.weatherstats.ca/

12 Clifton-Smith, M. J. and Wood, D. H. (2007). Further dual purpose evolutionary optimization of small wind turbine blades. J. Phys.: Conference Series 75012017 (9pp), doi: $\underline{10.1088 / 1742-6596 / 75 / 1 / 012017}$

13 Young, J. (2003). Wind Turbine Rotor Design. Undergraduate Thesis, Toronto: Ryerson University.

14 ANSYS $^{\circledR}$, Inc. (2010). ANSYS ${ }^{\circledR}$ Products Portfolio. Retrieved January 2010, from ANSYS ${ }^{\circledR}$ : http://www.ansys.com/products/default.asp

15 DreeseCODE Software, LLC. (2007). The Science Behind The Virtual Wind Tunnel. Retrieved October 2009, from DesignFOIL: http://www.designfoil.com/

16 Hepperle, M. (2006). Analysis of Airfoils. Retrieved October 2009, from JavaFoil: http://www.mh-aerotools.de/airfoils/javafoil.htm 